\title{
The Time-Varying Connectedness Between China's Crude Oil Futures and International Oil Markets: A Return and Volatility Spillover Analysis
}

\author{
Jiasha $\mathrm{Fu}^{1} \cdot$ Hui Qiao ${ }^{1}$
}

Received: 10 May 2021 / Accepted: 19 October 2021 / Published online: 2 November 2021

(c) The Author(s), under exclusive licence to Springer-Verlag GmbH Germany, part of Springer Nature 2021

\begin{abstract}
This paper examines the relationship between world crude oil markets following the introduction of Shanghai crude oil futures from the perspective of network connectedness based on the vector autoregressive model. The connectedness measurement method proposed by Diebold and Yilmaz (Econ J 119(534):158-171, 2009, Int J Forecast 28(1):57-66, 2012. https://doi.org/10.1016/j.ijforecast.2011.02.006, J Econom 182(1):119-134, 2014. https://doi.org/10.1016/j.jeconom.2014.04.012) is adopted to study a time-varying interdependence relationship. The empirical results show that the world crude oil markets exhibit a high degree of integration from both returns and volatility; however, the direction and magnitude contributed by each market varies significantly. Specifically, the West Texas Intermediate futures and Brent spot and futures markets were found to have the highest contributions to the world oil market over the entire sample period and take leading roles, whereas Dubai futures market was found to be the most important receiver, and has received the most spillover from other markets and passed it throughout the system. Shanghai crude oil futures is not yet highly connected with other markets. Moreover, heterogeneous changes in the direction, intensity, and persistence of the spillover were observed across markets after the outbreak of the COVID-19 pandemic in 2020. This study reveals the integration level of Shanghai crude oil futures and the dynamics of linkages between regional crude oil markets, which is of great significance for market participants, policymakers, and future researchers.
\end{abstract}

Keywords Market integration - Information spillover - Shanghai crude oil futures · Connectedness $\cdot$ Contagion $\cdot$ COVID-19

Hui Qiao

josieqiao00@163.com

Jiasha Fu

fujs@swufe.edu.cn

1 Research Institute of Economics and Management, Southwestern University of Finance and Economics, Chengdu 610074, Sichuan, People's Republic of China 
JEL Classification G14 · G15

\section{Introduction}

In recent years, regional oil markets have exhibited a co-movement trend. Several studies have measured the degree of integration of world crude oil markets based on correlations between prices or volatilities. For example, Jia et al. (2017) used data from 24 crude oil spots and Brent and West Texas Intermediate (WTI) crude oil futures to unveil the co-movement of regional oil markets; they confirmed that world crude oil market prices exhibit a concentric, transmissible, and collective network. Kuck and Schweikert (2017), as well as Ji and Fan (2015), examined the long-term cointegration relationships of five crude oil spots, namely WTI, Brent, Dubai, Tapis, and Bonny, and support the view that crude oil markets are globalized. Zhang et al. (2019) conducted a dynamic analysis of the connectedness of the returns and volatility of seven major regional crude oil spot markets around the world from 2002 to 2017; they found that global crude oil markets are well integrated, but that Asian oil prices are net receivers in both return and volatility networks.

Shanghai crude oil futures was listed on March 28th, 2018, and, to date, have been running for three years. Currently, the research on how the Asian oil market price changed after the listing of Shanghai crude oil futures and its impact on the degree of integration of the global crude oil market remains insufficient. It is therefore of necessity to introduce Shanghai crude oil futures into the analysis of crude oil market integration. First, the reference of Shanghai oil futures is a medium sour crude oil produced primarily in the Middle East, which is different from the major crude oil futures currently available worldwide, such as WTI and Brent futures. As a complement to the benchmark of Middle East crude oil, Shanghai crude oil futures have the potential to become an influential reference for the world crude oil market in the future (Yang and Zhou 2020). Secondly, as the world's largest crude oil importer and second-largest oil consumer (BP 2019), a large number of companies and investors are required to engage in risk-hedging and speculative behavior. In this regard, some previous studies have provided evidence of China's integration into the world crude oil market (Li and Leung 2011). Finally, three months after Shanghai crude oil futures were launched on the Shanghai International Energy Exchange (INE) on March 26th, 2018, it reached the third-highest trading volume in the world (Ji and Zhang 2019). The participation of international traders in the Asian crude oil spot market to hedge their risks will allow uncertainties from global finance to be transmitted to the Shanghai crude oil futures market (Yang et al. 2021).

In the wake of the recent global public health event COVID-19, the crude oil markets exhibit some unusual patterns, such as sharp price fluctuations, negative price, and the increase of the systematic risk in a very short period. Many studies have confirmed the total connectedness increases after sudden market events (Zhang and Boardstock 2018), but different from the previous crisis that originated from one sector, COVID19 influenced almost all sectors of the real economy simultaneously. Existing literature underlined that during the COVID-19 pandemic, the level of connectedness in assets (Bouri et al. 2021) and fossil fuels markets (Lin and Su 2021) had experienced a spike 
during COVID-19 pandemic, but the change was not structural or persistent. Therefore, we are curious about the response of global oil market, for the total connectedness, as well as the return and volatility network. Given that uncertainties of COVID-19, such studies have important implications for risk-controlling for energy-related industries.

Based on the situation described previously, this paper examines the connectedness between regional crude oil markets after the listing of Shanghai crude oil futures in terms of the return and volatility spillover transmission between regional oil markets. The paper aims to address the following questions: (1) whether the degree of global crude oil market integration has increased, and whether the intensity and direction of spillovers from different regional markets have changed. This paper follows the Diebold and Yilmaz spillover approach to specify the transmission of information for 10 crude oil markets. Moreover, a connectedness table is constructed and directed acyclic diagrams (DAGs) are used to visualize the spillover transmission within a network; (2) how the COVID-19 pandemic has affected the transmission mechanism in global crude oil markets. Via the use of dynamic rollingwindow regression and Antonakakis and Gabauer (2017) time-varying parameter VAR (TVP-VAR) approach, the results have shown a tremendous change of oil market connectedness, as well as the network structure amid the COVID-19 pandemic, but it is not persistent.

The marginal contributions of this paper are mainly summarized as follows. First, in addition to WTI and Brent crude oil futures, Dubai and Oman crude oil futures are also included in the system together with Shanghai crude oil futures. Compared to the existing literature, this paper provides a time-varying structure of the world crude oil market that covers a longer period of time and involves more regional markets. Second, this paper examines the information spillover effect in terms of both returns and intraday volatility. The analysis of returns can aid in the prediction of international crude oil price dynamics under different shocks, which can help realize trading strategies and reduce losses. From the perspective of practitioners, as commodity futures are an important tool for hedging risk, the measurement of volatility in different regional crude oil markets can aid in the construction of optimal hedging ratios and the choice of optimal portfolio strategies, which are important for developing risk management strategies in the crude oil market (Chang et al. 2010, 2011).

The remainder of this paper is structured as follows. First, a brief review of existing research on crude oil market integration and the measurement of price and volatility spillovers is provided in Sect. 2. Then, in Sect. 3, the methodology employed in this research is introduced, and Sect. 4 discusses problems with the data, provides summary statistics, and describes a preliminary analysis. In Sect. 5, the empirical results are reported and robustness tests are described. Finally, the conclusion of this research is provided in Sect. 6.

\section{Literature Review}

Since Adleman (1984) first stated that "The international crude oil market is a great pool," extensive studies have been conducted to examine whether regional crude oil markets are integrated. The earliest test of the hypothesis of this issue can be traced 
back to Weiner (1991), who rejected Adleman's (1984) hypothesis by examining the correlation between oil prices in different markets, and found that crude oil prices exhibit a high degree of regionalization.

These two opposing views have subsequently been tested empirically in various papers from the perspectives of the correlation or arbitrage between markets. For example, Bentzen (2007) applied an error correction model (ECM) to examine the causal relationships among the prices of three major oil markets from 1988 to 2004, and found a bi-directional causal relationship between crude oil prices, thereby supporting the hypothesis of global crude oil market integration. Ji and Fan (2015) used the ECM to study the long-run equilibrium of four crude oil spot market prices from 2000 to 2014; they confirmed that the world crude oil market began to diverge after 2010, when WTI lost its leading role and diverged from the world market. Gulen (1999) examined the covariance between 15 crude oil spot prices in terms of arbitrage possibilities, and found co-movement between crude oils with similar API gravities and sulfur contents. Kleit (2001) observed that the arbitrage cost between regions decreases over time, and argued that regional crude oil markets have gradually become more integrated. Milonas and Henker (2001) studied the price spread between Brent and WTI crude oil, and concluded that these markets had not yet become fully integrated.

In terms of empirical methodology, with the development of multivariate and time-varying models, multivariate generalized autoregressive conditional heteroscedasticity (GARCH) models, such as the BEKK-GARCH, CCC-GARCH, and DCC-GARCH models, have been used to study spillovers between regional markets (Chang et al. 2010; Jin et al. 2012). Moreover, to address the shortcomings of multivariate GARCH models that cannot capture dynamic changes, some time-varying vector autoregressive (VAR)-GARCH models have been developed, such as the time-varying parameter VAR model with stochastic volatility (TVP-VAR-SV) used by Liu and Gong (2020). In addition, principal component analysis has also been used to identify the correlation matrix between regional crude oil markets (Dai et al. 2016), thereby enabling the accommodation of a wider range of markets.

However, these methods have several limitations. For example, most multivariate GARCH models are difficult to estimate and unable to reveal the direction and time-varying characteristics of volatility spillovers. Because of their high dependence on identification and economic theory, the coefficients and forecast error variance decomposition (FEVD) results obtained from VARs are difficult to interpret in a reasonable way. Diebold and Yilmaz (2009) therefore constructed a spillover index using the VAR model and FEVD method to quantify the return and volatility spillover. Via the introduction of the realized volatility of the market, the VAR model can support the endogenization of volatility across large amounts of markets simultaneously, thereby surmounting the shortcomings of the traditional GARCH model. The FEVD was later replaced by the generalized FEVD (GFEVD) by Diebold and Yilmaz in 2012, and, in 2014, they developed an analysis framework based on the spillover index, constructed a connectedness table, and internalized it with the network topology to visualize the intensity and direction of spillover. Due to its ease of use and effective explanatory power, this method has been widely used in the study of energy markets, including crude oil markets (Zhang 2017; Zhang et al. 2019; Liu 
and Gong 2020), natural gas markets (Broadstock et al. 2020), and electricity markets (Han et al. 2020).

Moreover, recent models have extended the approach by allowing to study effects of asymmetric shock (Baruník et al. 2016), heterogenous frequency-domains (Baruník and Křehlík 2018), and providing more table rolling-window results by Bayesian VAR (Korobilis and Yilmaz 2018) and TVP-VAR approach (Antonakakis and Gabauer 2017).

This paper adopts the Diebold and Yilmaz (2012) approach to revisit the global crude oil market connectedness after the incorporation the newly developed Shanghai crude oil future. We apply this method to analyze the return and volatility connectedness between regional oil markets, and its dynamics during COVID-19 pandemic. We also employ the TVP-VAR method to confirm the rolling-window results. We expected that the crude oil market showed a high level of integration, and the connectedness between markets had changed during the crisis compared to the normal period.

\section{Methodology}

\subsection{VAR and GFEVD}

The spillover index originally proposed by Diebold and Yilmaz (2009), which is also called the DY index, is a technique based on the FEVD in VAR models. It represents the extent to which changes in one variable can be explained by another variable when a unit of exogenous shock occurs. As described previously, the traditional approach including the GARCH-type models to the study of return and volatility spillovers requires researchers to make reasonable preconceptions about the underlying interaction mechanism between the variables under study, which is particularly difficult when studying correlations between financial markets. In comparison, the most important advantage of the DY index is that it provides widely accepted interpretations of the coefficients obtained by VAR.

Here, a brief summary of the spillover index and connectedness table constructed by Diebold and Yilmaz (2012) is provided. First, consider a K-variable VAR(p) process, as given by Eq. (1):

$$
Y_{t}=C+\sum_{i=1}^{p} \Phi_{i} Y_{t-i}+\varepsilon_{t}, \# 1
$$

where $Y_{t}$ is the $K$-dimension column vector, each element in which should be a covariance stationary process, and $\varepsilon_{t}$ is a vector of independent and identically distributed (i.i.d.) disturbances that follows an $N(0, \Sigma)$ distribution. The moving average (MA) representation of a VAR(p) process can be expressed as $Y_{t}=\sum_{i=0}^{\infty} A_{i} \in_{t-i}$, and the $k \times k$ coefficient matrix $A_{i}=\sum_{p=1}^{p} \Phi_{p} A_{i-p}$, where $A_{0}$ denotes an identity matrix $I(k)$. The use of MA coefficients can help identify how the compositions interact with each other. Consider an $N$-step forecast of $Y_{t}$; its forecast error can be decomposed into a series of independent shocks from each variable via Cholesky 
factorization. Furthermore, because the results of Cholesky factorization are sensitive to the order of variables, Diebold and Yilmaz (2012) worked with the GFEVD exploited by Koop et al. (1996) and Pesaran and Shin (1998) to allow correlated shocks, and the KPPS H-step FEVD is given by Eq. (2):

$$
d_{i j}(H)=\frac{\sigma_{i i}^{-1} \sum_{h=0}^{H}\left(e_{i}^{\prime} A_{h} \Sigma e_{j}\right)^{2}}{\sum_{h=0}^{H}\left(e_{i}^{\prime} A_{h} \Sigma A_{h}^{\prime} e_{j}\right)}
$$

where $\mathrm{d}_{\mathrm{ij}}(H)$ estimates the percentage of the H-step forecast error variance of $Y_{i}$ that can be explained by $Y_{j}, \Sigma=E\left[\in_{t} \in_{t}^{\prime}\right]$ is the variance-covariance matrix of the error term $\in_{t}, \sigma_{i i}$ is the $i$ th diagonal element in $\Sigma$, and $e_{i}$ is the selection vector, which is equal to 1 for the $i$ th element; otherwise, it is equal to 0. Because Diebold and Yilmaz (2012) pointed out that $\sum_{j=1}^{K} d_{i j}(H)$ is not necessarily equal to 1 , the elements in each entry of the variance decomposition matrix are normalized to obtain the spillover index, as follows

$$
\hat{d}_{i j}(H)=\frac{d_{i j}(H)}{\sum_{j=1}^{K} d_{i j}(H)} .
$$

\subsection{Measuring the Spillover}

The variance of the forecast error is used to explain to what extent the change of one variable is caused by another; therefore, the total spillover measures the contribution of shocks from the spillover of each series to the total forecast error variance, and is calculated as follows.

$$
S(H)=\frac{\sum_{i, j=1(i \neq j)}^{K} \hat{i}_{i j}(H)}{\sum_{i, j=1}^{K} \hat{d}_{i j}(H)} \times 100=\frac{\sum_{i, j=1(i \neq j)}^{K} \hat{d}_{i j}(H)}{K} \times 100
$$

In addition, the interaction relationships between specific variables are also of interest. For the pairwise relationship between variables $i$ and $j$, the directional spillover is defined as $S_{i \leftarrow j}^{H}=\hat{d}_{i j}(H)$, which represents the pairwise directional connectedness from $j$ to $i$. Correspondingly, the pairwise directional spillover from $i$ to $j$ is $S_{i \rightarrow j}^{H}=\hat{d}_{j i}(H)$. The net pairwise spillover provides a more accurate view of the information transmission among markets. The net pairwise spillover from $j$ to $i$ is the difference between the spillover from $i$ to $j$ and the spillover from $j$ to $i$, i.e., $S_{i j}^{H}=\hat{d}_{i j}(H)-\hat{d}_{j i}(H)$, where $S_{i j}=0$ for all $i=j$ in nature. If the value is greater than 0 , it means that $i$ is a net spillover transmitter relative to $j$; if the value is less than 0 , it means that $i$ is a net receiver.

Using the set of indexes associated with the VAR-based framework, Diebold and Yilmaz (2014) constructed a connectedness table, as shown in Table 1. The element $(i, j)$ represents the estimated contribution to the forecast error variance of market $i$ from the shocks of market $j$. To measure the directional connectedness from $i$ to all other $j$, Diebold and Yilmaz (2014) further defined the following three measurements. 
1. Contributions from others: The spillover received by $i$ from all other $j$, $S_{i \leftarrow}^{H}=\Sigma_{j=1}^{K} \hat{d}_{i j}(H), j \neq i$, which in the connectedness table is the sum of the elements of each entry excluding the variable $i$ itself. This value is also equal to 1 minus the variance contribution from itself due to normalization.

2. (Contributions to others: The spillover transmitted by $i$ to all other $j$, $S_{\leftarrow i}^{H}=\Sigma_{i=1}^{K} \hat{d}_{i j}(H), i \neq j$, which is the sum of the elements in each column excluding variable $i$.

3. Net contributions to others: The net total directional spillover for market $i$, $S_{i}^{H}=S_{\leftarrow i}^{H}-S_{i \leftarrow}^{H}$.

Based on these definitions, when $S_{i}^{H}>0$, market $i$ provides higher explanatory power to the shocks from other markets relative to what can be explained by market $j$; therefore, this market is a net information transmitter. Correspondingly, $S_{i}^{H}<0$ implies that market $i$ transmits less spillover to other markets relative to what can be explained by the shocks from other markets $j$; therefore, this market is a net information receiver.

\section{Data and Descriptive Statistics}

\subsection{Data Selection}

To examine the return and volatility spillover effects among the global crude oil markets, price information was collected for a total of 10 influential oil futures or spots worldwide. On the futures side, the five most-traded contracts were selected, namely the Brent crude oil futures in the Intercontinental Exchange (ICE) (fbrent), the Platt Dubai crude oil futures in the Tokyo Commodity Exchange (TOCOM) (fdubai), the Oman crude oil futures in the Dubai Mercantile Exchange (DME) (foman), the medium sour crude oil futures in the Shanghai International Energy Exchange (INE) ( $f$ shfe), and the West Texas Intermediate (WTI) crude oil futures in the New York Mercantile Exchange (fwti). More detailed information with respect to these five oil futures contracts is presented in Table 2. Regarding oil spots, the WTI (swti), Brent (sbrent), Maya (smaya), Dubai (sdubai), and Oman (soman)

Table 1 The connectedness table

\begin{tabular}{llllll}
\hline & $Y_{1}$ & $Y_{2}$ & $\ldots$ & $Y_{k}$ & From others \\
\hline$Y_{1}$ & $\hat{d}_{11}(H)$ & $\hat{d}_{12}(H)$ & $\ldots$ & $\hat{d}_{1 k}(H)$ & $\sum_{J=1}^{\mathrm{k}} \hat{d}_{1 j}(H)$ \\
$Y_{2}$ & $\hat{d}_{21}(H)$ & $\hat{d}_{22}(H)$ & $\ldots$ & $\hat{d}_{2 k}(H)$ & $\sum_{J=1}^{\mathrm{k}} \hat{d}_{2 j}(H)$ \\
$\ldots$ & $\ldots$ & $\ldots$ & & $\ldots$ & $\ldots$ \\
$Y_{k}$ & $\hat{d}_{k 1}(H)$ & $\hat{d}_{k 2}(H)$ & $\ldots$ & $\hat{d}_{k k}(H)$ & $\sum_{J=1}^{\mathrm{k}} \hat{d}_{k j}(H)$ \\
To others & $\sum_{i=1}^{\mathrm{k}} \hat{d}_{i 1}(H)(i \neq 1)$ & $\sum_{i=1}^{\mathrm{k}} \hat{d}_{i 2}(H)(i \neq 2)$ & $\ldots$ & $\sum_{i=1}^{\mathrm{k}} \hat{d}_{i k}(H)(i \neq k)$ & $\frac{1}{k} \sum_{i, j=1}^{\mathrm{k}} \hat{d}_{i j}(H)(i \neq j)$ \\
\hline
\end{tabular}

The connectedness table is constructed referred to Diebold and Yilmaz (2014) 
crude oil spot markets were selected. Excluding the Shanghai crude oil futures, the remaining four futures contracts were used as benchmarks for long-term crude oil trading in different regions: Brent crude oil was considered the main reference for trades to or from Europe; WTI crude oil was the main choice for North America; Oman and Dubai crude oils were the main choices for exports from the Middle East and Far East. while the Dubai Platts oil price index was used as a benchmark for the Asia-Pacific region.

The daily prices for the 10 markets from March 27th, 2018 to December 1st, 2020 were downloaded from Bloomberg, and included the highest price, the lowest price, and the closing price. To avoid the effects of negative prices for some contracts on April 20, 2020 (i.e., fwti, smaya, swti), they were treated as outliers and the prices for all series on that day were eliminated (Cai et al. 2009). As shown in Table 2, because the trading unit per Dubai futures contract is inconsistent with several other futures contracts, the price of Dubai futures was scaled from the price per contract $(50 \mathrm{~kL})$ to the price per 1000 barrels. In addition, the noteworthy problem of nonsynchronous trading across futures exchanges was considered, which is discussed in more detail in the following section.

\subsection{The Non-synchronous Trading Problem}

The non-synchronous trading problem arises as financial markets in different geographical regions operate with different opening and closing times (Eun and Shim 1989). There are two types of non-synchronous trading problems in crude oil markets, namely the different working and closure days within a year, and the different trading hours in a trading day.

The deletion of unmatched trading days is one of the most widely applied methods to deal with the problem of different closure days (Andersen et al. 2003). However, the direct deletion of non-trading days may result in a substantial contraction in sample size, especially when many time series are used in a study. Instead, there are two other applicable methods, namely the model-based method and the simple interpolation method via the use of the sample mean, medium, or the moving average (MA) of the observed values to fill the values on the missing days. In model-based correction methods, missing data are filled based on the statistical information of the observed values, which maintains the integrity of the original data; however, as mentioned by Martens and Poon (2001), this is sensitive to model specifications. In this study, a direct correction of the data, rather than a model-based correction, was employed for simplicity. The working days given by the Shanghai INE were taken as the benchmark, and the interpolation method was used to fill the missing data for other price series.

Unlike the 24-h trading system implemented in the crude oil spot market, as presented in Table 2, different futures markets have different opening and closing times, i.e., non-synchronous trading hours, which may lead to inconsistencies in the information contained in the prices of different markets on the same day. This will induce more serious problems when studying the interaction and information transmission between several markets. Several studies have noted that the correlations between 


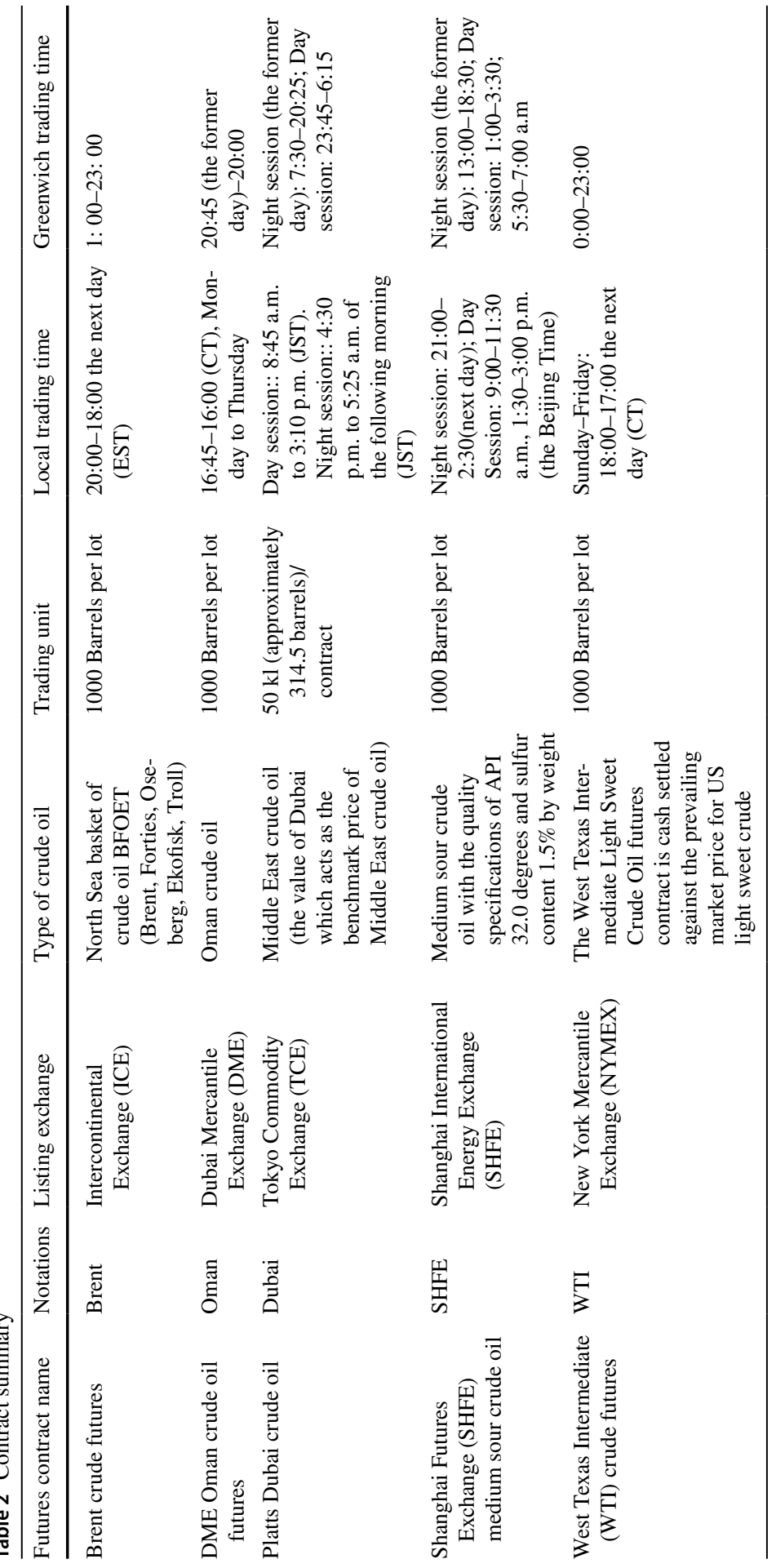


non-synchronous returns are substantially underestimated, which will further lower the level of integration between the markets (Schotman and Zalewska 2006).

In Table 2, the local trading times for the oil futures have been converted into Greenwich time. The Dubai crude oil futures open at 7:00 GMT on the former day and close at 6:15 GMT. The Shanghai crude oil futures open with the start of the night session at 13:00 GMT (the opening time of the night session) on the former day and close with the end of the day session at 7:00 GMT (the closing time of the day session). The Oman crude oil futures open at 20:45 GMT on the former day and close at 20:00 GMT. The opening time of ICE Brent crude oil futures is 1:00 GMT, and the closing time is 23:00 GMT. The WTI light crude oil futures open at 0:00 GMT and close at 23:00 GMT. To clearly illustrate the trading order of five crude oil futures, Fig. 1 presents the timelines of the five contracts in GMT, from which it can be seen that the closing order of the five futures markets is SHFE, Dubai, Oman, WTI, and Brent. When the Dubai and Shanghai oil futures end their trading day, the other three markets have just opened.

Some studies have used low-frequency data (i.e., weekly and monthly data) to avoid this problem. However, this approach is not well-suited for samples with short time periods and for the examination of the interdependence and interactions across markets, i.e., the price or volatility spillovers in higher-frequency time domains. The method of overlapping multiple returns adopted by Forbes and Rigobon (2002) is an applicable way to deal with the daily-frequency framework, where the returns (volatilities) for each series in different countries are computed by the two-day rolling average. Another frequently adopted correction method is the use of priors and lags of the independent variables (Scholes and Williams 1977; Zhang and Wang 2014). In the present study, a two-day rolling average approach when dealing with opening and closing times and non-synchronous trading times was chosen due to the differences in time zones. After completing the entire data processing regime described in Sects. 4.1 and 4.2, the data for each market over a total of 649 trading days were ultimately obtained.

\subsection{Measuring the Daily Return and Volatility}

This study aims to measure the return and volatility spillover for 10 world oil futures and spots (fbrent, fdubai, foman, fshfe, fwti, sbrent, sdubai, smaya, soman, and swti).

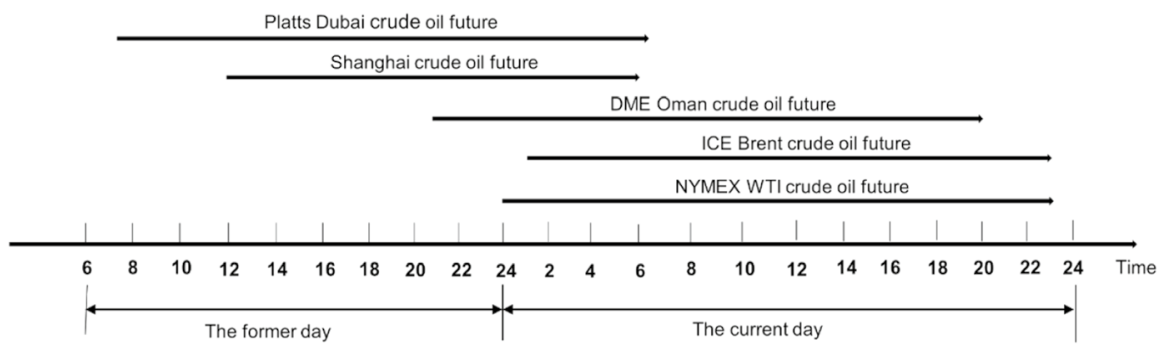

Fig. 1 Exchange trading hours 
For each day and market, the daily price observations were used to calculate the daily returns and volatilities. The return is defined as the log difference of the daily closing price, as follows.

$$
r_{i t}=\ln \left(p_{i t}\right)-\ln \left(p_{i t-1}\right)
$$

To measure the daily volatility, the range-based method was applied by using the highest and lowest daily prices (Diebold and Yilmaz 2012; Zhou et al. 2012; Han et al. 2020). For market $i$ at time $t$, the realized volatility is given by Eq. (6):

$$
\tilde{\sigma}_{i t}^{2}=0.361\left[\ln \left(p_{i t}^{\max }\right)-\ln \left(p_{i t}^{\text {low }}\right)\right]^{2},
$$

where $p_{i t}^{\max }$ and $p_{i t}^{\text {low }}$ are respectively the highest and lowest prices of market $i$ at time $t$. Then, the annualized daily percent volatility was further obtained as $\hat{\sigma}_{i t}=100 \sqrt{365 \cdot \tilde{\sigma}_{i t}^{2}}$.

Figure 2 presents the intraday price volatilities of the futures and spots, respectively. The daily volatilities for all markets were found to fluctuate sharply over the sample period, and reached their respective highest levels in March and April 2020, when the COVID-19 crisis first erupted. This suggests the need for the further study of individual market performance during this period.

The descriptive statistics for the returns and volatilities for each regional oil market are reported in Table 3, which conveys several facts. First, the average returns of different oil futures and spots were close to 0 , and were either positively or negatively skewed. In addition, all series were found to exhibit a kurtosis greater than 3 , thereby exhibiting stylized properties of the financial data. Second, with the exception of the Oman crude oil futures (14.2225), the average annualized volatility for other markets was greater than 35. As can be seen from the Fig. 2, the original series were positively skewed and highly leptokurtic, which may strongly violate the assumptions of the GFEVD. To maintain the normality property and the robustness of the estimation results, a natural logarithm transformation was conducted and its descriptive statistics are also provided, which demonstrate a better normality property. Third, Augmented-Dickey Fuller (ADF) tests were performed on the three groups of series to test whether they were stationary. The results show that all the returns and log volatility series were stationary, while some of the original volatility series were non-stationary. In summary, the original volatilities are replaced with the natural log-transformed intra-day volatilities in the following content without particular specification.

Figure 3 exhibits the correlation matrix between returns (left panel) and volatilities (right panel). The returns and volatilities in all 10 markets were found to be pairwise positively correlated, indicating that when the return (or volatility) in one market changes, the rest of the markets respond in the same direction, thereby supporting the hypothesis of market co-movement. The correlation matrix for each series was organized by the angular order of the eigenvectors (AOE) so that variables with similar correlations were positioned adjacently (Friendly 2002). In Fig. 3, the Brent and WTI futures and spot markets and Maya spot market are adjacent to each other in the correlation matrix of returns and intra-day volatilities, exhibiting a 

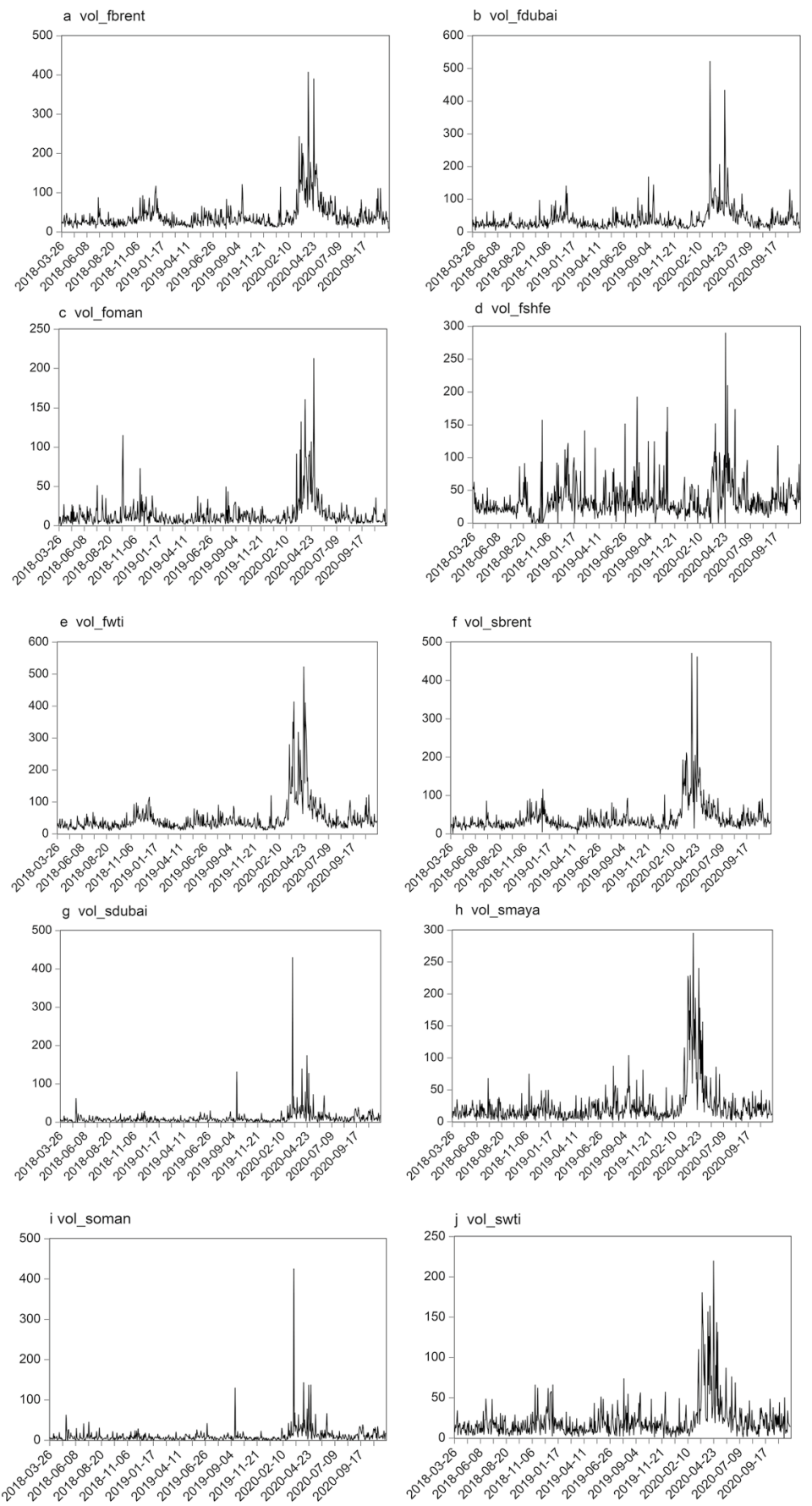

Fig. 2 Intra-day volatility for oil futures and spots 
Table 3 Table descriptive statistics for crude oil markets returns and volatilities (logarithm)

\begin{tabular}{|c|c|c|c|c|c|c|c|c|}
\hline & Mean & Median & Maximum & Minimum & SD & Skewness & Kurtosis & $\begin{array}{l}\text { ADF test } \\
\text { (level) }\end{array}$ \\
\hline \multicolumn{9}{|c|}{ Panel A: return } \\
\hline r_fbrent & -0.00002 & 0.00184 & 0.19077 & -0.27575 & 0.03052 & -0.63686 & 19.44127 & $-23.2935^{* * *}$ \\
\hline r_fdubai & -0.00037 & 0.00000 & 0.27088 & -0.38176 & 0.03271 & -3.54644 & 60.79619 & $-31.5317 * * *$ \\
\hline r_foman & -0.000189 & 0.00169 & 0.18934 & -0.31352 & 0.03520 & -0.76804 & 20.70553 & $-26.9980 * * *$ \\
\hline$r_{-}$fshfe & -0.000575 & -0.00015 & 0.11578 & -0.10465 & 0.02395 & -0.39125 & 6.97954 & $-21.5028 * * *$ \\
\hline r_fwti & 0.000333 & 0.00095 & 0.31963 & -0.28221 & 0.04096 & 0.29241 & 25.04929 & $-7.26198^{* * *}$ \\
\hline r_sbrent & -0.000104 & 0.00085 & 0.19778 & -0.33590 & 0.03312 & -1.31301 & 25.86479 & $-26.4641 * * *$ \\
\hline r_sdubai & 0.0001 & 0.00101 & 0.31177 & -0.35635 & 0.03331 & 0.01253 & 39.67244 & $-25.2589^{* * *}$ \\
\hline r_smaya & 0.00096 & 0.00194 & 0.53976 & -0.36010 & 0.05520 & 1.75263 & 32.16946 & $-4.49451 * * *$ \\
\hline r_soman & 0.000148 & 0.00074 & 0.25727 & -0.33984 & 0.03522 & -0.13852 & 28.96822 & $-6.12560^{* * *}$ \\
\hline r_swti & 0.000517 & 0.00105 & 0.42583 & -0.28138 & 0.04683 & 1.27296 & 29.73087 & $-8.7882 * * *$ \\
\hline \multicolumn{9}{|c|}{ Panel $B$ : original intra-day daily volatility } \\
\hline vol_fbrent & 40.6099 & 29.9317 & 407.3015 & 8.2766 & 37.0929 & 4.4958 & 34.0494 & -2.448 \\
\hline vol_fdubai & 38.1899 & 29.0989 & 521.8791 & 3.9788 & 37.2257 & 6.4456 & 68.9967 & $-5.0715^{* * *}$ \\
\hline vol_foman & 14.2225 & 9.0906 & 212.7762 & 0.0000 & 18.4988 & 4.9181 & 37.0478 & $-2.8912 * *$ \\
\hline vol_fshfe & 36.0936 & 28.1707 & 289.8935 & 0.0000 & 29.6043 & 2.8335 & 16.3508 & $-7.9703^{* * *}$ \\
\hline vol_fwti & 48.3626 & 33.4680 & 522.8901 & 10.5336 & 51.8530 & 4.5805 & 29.8065 & $-4.8178^{* * *}$ \\
\hline vol_sbrent & 40.4507 & 30.1350 & 470.8477 & 0.0000 & 39.3991 & 5.4304 & 48.6990 & -2.4502 \\
\hline vol_sdubai & 10.9653 & 6.5708 & 429.7549 & 0.0000 & 22.0752 & 12.2104 & 210.0547 & $-7.4247 * * *$ \\
\hline vol_smaya & 24.6498 & 15.7436 & 295.0593 & 1.1869 & 32.2062 & 4.1727 & 24.6805 & $-3.4946 * * *$ \\
\hline vol_soman & 11.0274 & 6.5176 & 425.1217 & 0.0000 & 21.7012 & 12.1962 & 212.8280 & $-7.7972 * * *$ \\
\hline vol_swti & 21.1525 & 15.2056 & 219.7351 & 0.0000 & 22.9644 & 3.9407 & 24.1123 & $-2.7569 *$ \\
\hline \multicolumn{9}{|c|}{ Panel C: natural logarithm-form of the intra-day daily volatility } \\
\hline v_fbrent & 1.5146 & 1.4761 & 2.6099 & 0.9179 & 0.2600 & 0.8798 & 4.1782 & $-4.1236 * * *$ \\
\hline v_fdubai & 1.4843 & 1.4639 & 2.7176 & 0.5998 & 0.2698 & 0.5719 & 4.2440 & $-4.7495 * * *$ \\
\hline v_foman & 0.9814 & 0.9586 & 2.3279 & 0.0000 & 0.3570 & 0.5192 & 3.6325 & $-5.4900^{* * *}$ \\
\hline v_fshfe & 1.4287 & 1.4498 & 2.4622 & -0.7481 & 0.3833 & -1.5753 & 8.4250 & $-5.6750^{* * *}$ \\
\hline v_fwti & 1.5730 & 1.5246 & 2.7184 & 1.0226 & 0.2743 & 1.0914 & 4.8087 & $-3.9244 * * *$ \\
\hline V_sbrent & 1.5061 & 1.4791 & 2.6729 & -0.0158 & 0.2776 & 0.1846 & 6.8575 & $-5.1731 * * *$ \\
\hline v_sdubai & 0.7916 & 0.8176 & 2.6332 & -0.8143 & 0.4590 & -0.1832 & 3.7887 & $-6.6818^{* * *}$ \\
\hline v_smaya & 1.2037 & 1.1971 & 2.4699 & 0.0744 & 0.3846 & 0.2320 & 3.7072 & $-4.5613^{* * *}$ \\
\hline v_soman & 0.7903 & 0.8141 & 2.6285 & -0.8178 & 0.4682 & -0.2386 & 3.7756 & $-6.6986^{* * *}$ \\
\hline v_swti & 1.1732 & 1.1820 & 2.3419 & -0.4055 & 0.3590 & -0.0660 & 3.9953 & $-4.2045^{* * *}$ \\
\hline
\end{tabular}

The ADF test statistics present the t-statistics of the Augmented Dickey Fuller (ADF) test. The critical value for $\mathrm{ADF}$ test under $10 \%, 5 \%$ and $1 \%$ significant level is -3.44172 , where $*, * *$, *** denotes $10 \%$, $5 \%$ and $1 \%$ level of significant, respectively. The lag selection is based on the Akaike Information Criteria (SIC)

high degree of correlation and interaction. Moreover, the figure shows that Shanghai crude oil futures and Dubai and Oman crude oil spots and futures were found to be less correlated with other crude oil contracts in terms of returns and intraday volatility; this is likely because their underlying assets are produced in the Middle East or Asia-Pacific regions, unlike the others in the system, which are mainly produced in the Europe and the Americas. 
a returns

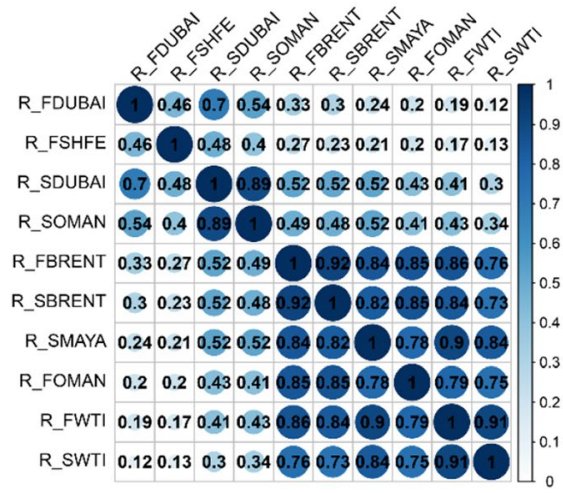

b volatility

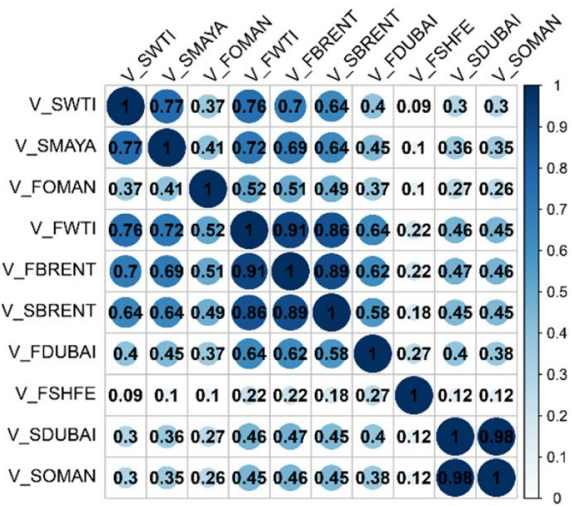

Fig. 3 The correlation analysis

Table 4 reports the results of the VAR-based Granger causality tests, which intuitively present the short-term lead-lag relationships between the returns and volatilities of crude oil spots and futures. In the table, $\left(R_{i}, R_{j}\right)$ represents the $p$-value of the rejection of the Granger causality from $i$ to $j$. Using the $5 \%$ significant level as the benchmark, simple maps were used to demonstrate the linkages between these variables.

Figure 4 plots the respective relationships between the returns and daily volatilities of the contracts. An arrow from variable $i$ to variable $j$ represents that $i$ "Granger-causes" $j$. In both panels of Fig. 4, the bio-directional Granger causality relationships are widely exhibited in the system, which indicates that the system is highly interdependent. When an exogenous innovation occurs in one of the oil markets, it will transmit across the markets and influence the entire system.

In Fig. 4, each node represents a contract. The size of a node indicates the number of significant Granger causality relationships it contains; the larger the node, the stronger the centrality in this system, and the more it receives shocks from other variables and spreads them throughout the system. The shade of a node indicates whether it is a net return (or volatility) transmitter or receiver; the darker the color, the stronger the net effect of affecting other nodes. Precisely, in panel (a), the WTI spots are shown to be "gateway" crude oil contracts in terms of return. In panel (b), the volatility of WTI futures leads to the volatility of other contracts, which "Granger-causes," but is not "Granger-caused" by, the returns or volatilities of other crude oils. In contrast, Shanghai crude oil futures are demonstrated to be strongly "Granger-caused" by other assets positioned at the end of the network; it receives innovations from, but does not largely affect the returns and volatilities of, other crude oil contracts. 


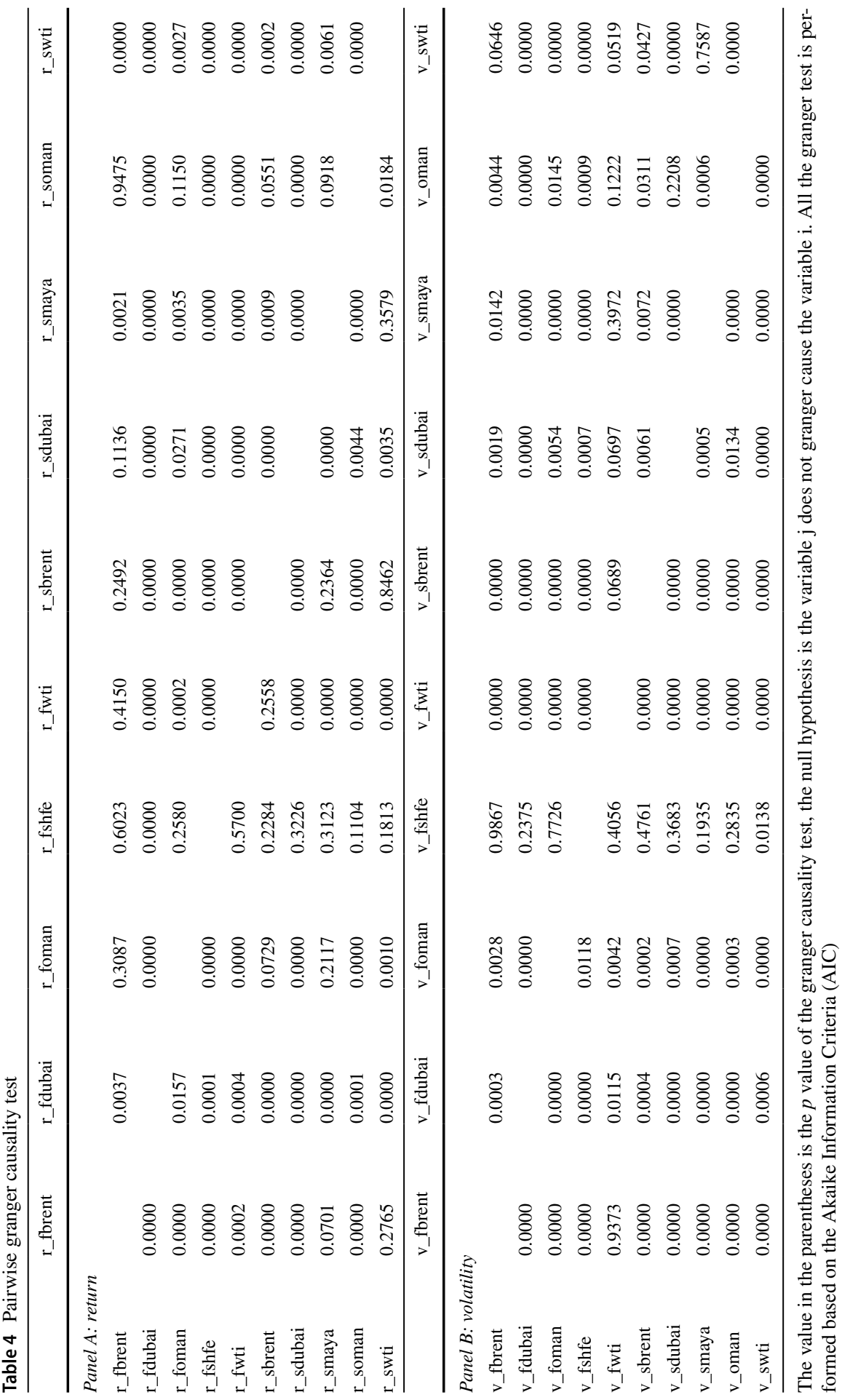




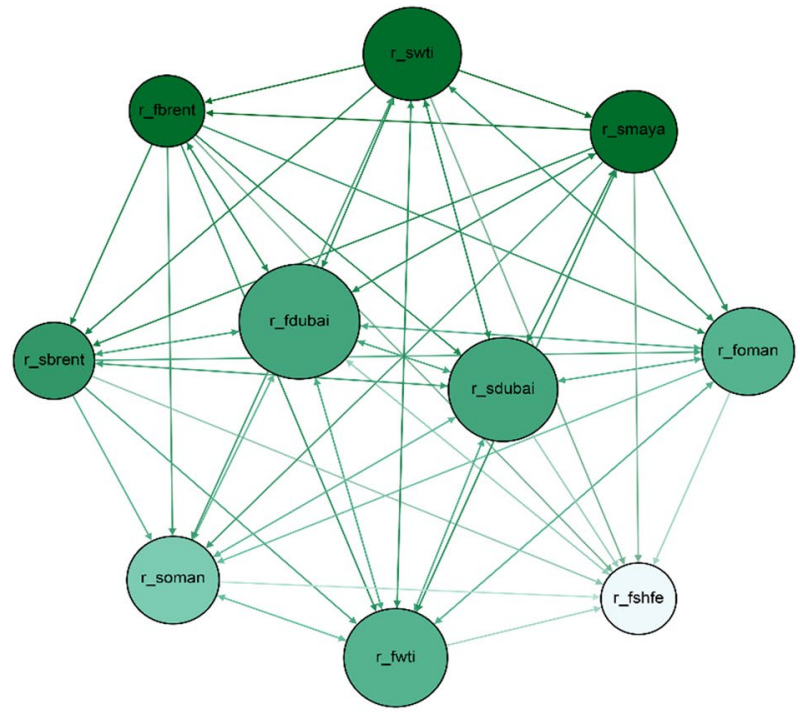

a return

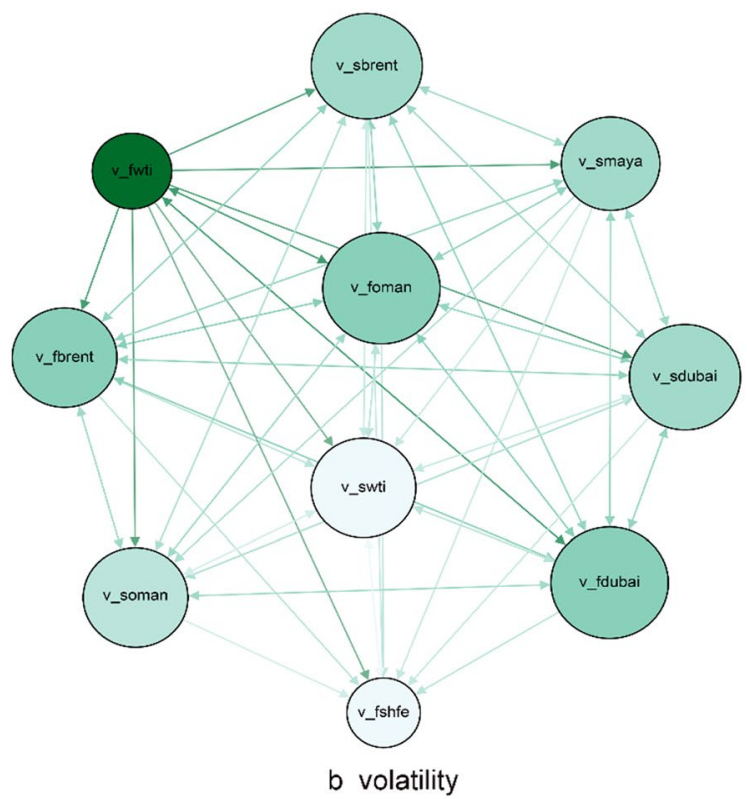

Fig. 4 Pairwise granger causality relationship (return and volatilities, at 5\% significant level), Note The node size denotes the existed quantities of pairwise significant granger causality relations. A large node indicates that it is highly integrated to the system. A unidirectional arrow that starts from node $\mathrm{i}$ to node $\mathrm{j}$ indicates i granger cause $\mathrm{j}$, a bio-directional arrow indicates the bio-directional granger causality relation 


\section{Empirical Results}

The method by Diebold and Yilmaz $(2012,2014)$ was employed to measure the direction and intensity of the return and volatility spillovers across the 10 crude oil markets.

\subsection{Model specifications}

First, VAR models were constructed for the returns and volatilities of each of the 10 markets. Three parameters are required in the VAR variance decomposition analysis: the lag length $(p)$ included in the VAR model, the prediction horizon $(H)$ of the FEVD, and the number of observations in a rolling window $(w)$ for the rollingwindow analysis. As is going to be reported in Sect. 5.2, the full-sample VAR was used to complete the static spillover analysis. Adopting the Schwarz information criteria (SIC), the optimal lag length of 3 was chosen for returns, and the optimal lag of 2 was chosen for volatility to complete the static spillover analysis. The GFEVD was obtained for up to 10 periods $(H=10)$. In Sect. 5.3, as an extension of the static VAR, a rolling-window VAR estimation was made to obtain a dynamic spillover series. The sample length of each regression is called the rolling window $(w)$. One VAR was estimated over the window, and the spillover index was then calculated. A 120 -day rolling window $(w=120)$ with a step of 1 day was chosen. To provide a robust assessment of the results, the data were split into three subsamples, and the results are reported in Sect. 5.4.

\subsection{Full-Sample Spillover Analysis}

The off-diagonal elements of Tables 5 and 6 collect the mean return and volatility connectedness index, of ten crude oil futures and spots prices, respectively. It was found that the total return and volatility spillovers between all ten crude oil markets were $85.2 \%$ and $64.3 \%$, respectively. This implies that the most of the forecast error variances are due to the spillover effect among regional markets.

In Table 5, Brent oil spot (115.0\%), WTI oil futures (113.8\%), and Brent oil futures $(114.1 \%)$ are the most significant transmitters for directional connectedness. About the shocks transmitted from the system to each variable, Dubai $(90.1 \%)$ futures is the most significant receiver. The net total directional connectedness in the bottom row shows that Dubai $(-50.1 \%)$ and Shanghai futures $(-59.1 \%)$ are two dominant net receivers of return.

As regard to the volatility spillover, Table 6 shows three dominant net transmitters of shocks to the system are WTI futures (71.6\%), Brent future (42.2\%), and Brent spot $(32.5 \%)$. The most relevant receiver of volatility shocks is Dubai futures $(84.8 \%)$. Similarly, the net volatility connectedness results show that Dubai $(-73.6 \%)$ and Shanghai oil futures $(-26.7 \%)$ are net receivers of volatility.

Overall, these results indicate that Brent futures, WTI futures and Brent spot play leading roles in the global crude oil market, that is, they are price makers. In 


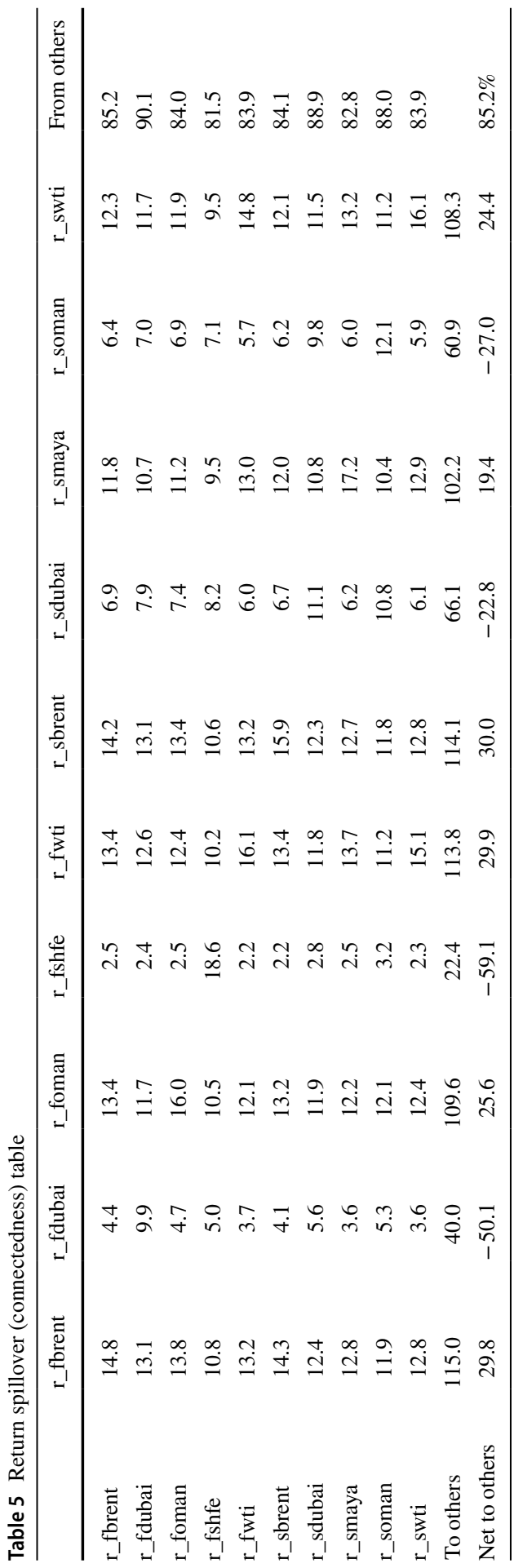




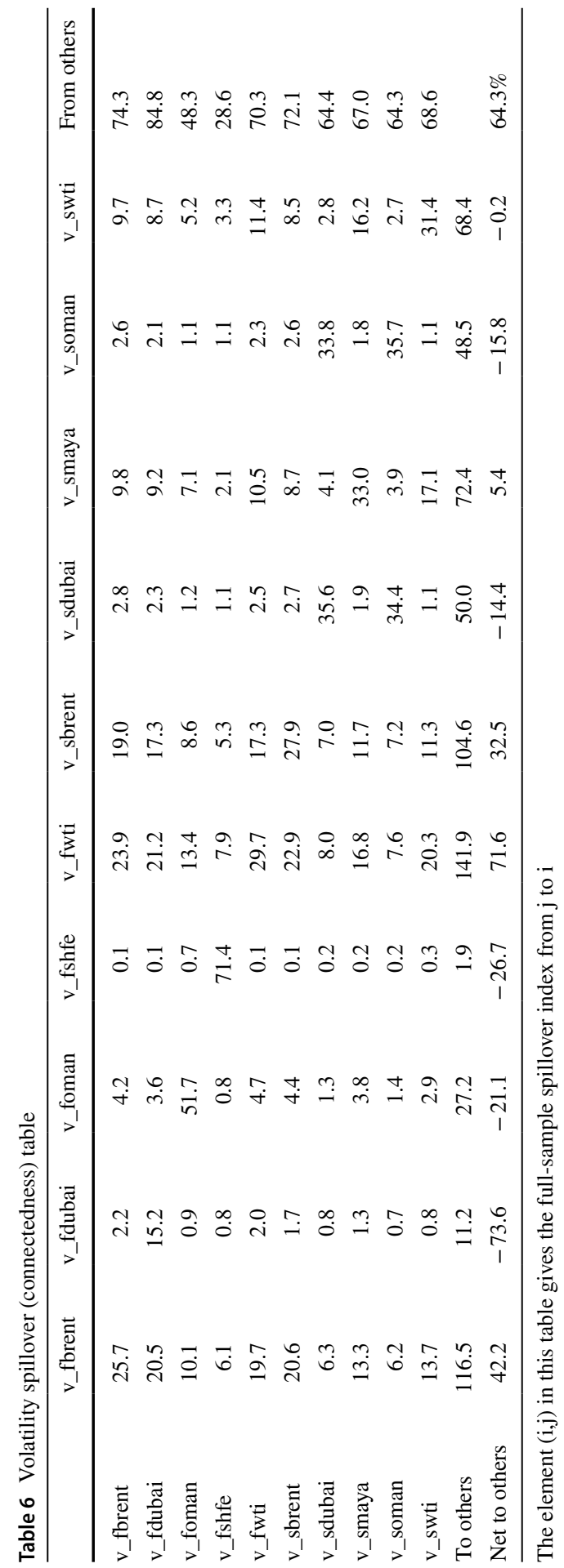


contrast, Dubai and Shanghai futures are mostly affected by shocks from other markets. However, Shanghai futures is the one that least connected to the system, since Shanghai futures receive the least spillover from the system for both return $(22.4 \%)$ and volatility (1.9\%). To illustrate the different roles of Shanghai and Dubai futures, the pairwise spillover index in Table 7 indicates that, Dubai futures is the dominant recipient from WTI futures, Brent spot, and Brent futures for both return $(-8.9 \%$, $-8.9 \%$ and $-8.6 \%$ respectively) and volatility $(-19.2 \%,-18.3 \%$ and $-15.6 \%$, respectively) shocks, the level is found to be much higher than the magnitudes of the spillover to Shanghai crude oil futures.

Figure 5 plots the connectedness map, the arrows are always unidirectional, and point from a transmitter to a receiver. With reference to Fig. 5a, Shanghai oil futures were found to serve as a net return receiver for all the remaining markets performing as the end of the network, while WTI futures were found to be the gateway in the system, offering higher explanatory power to the other oil price shocks, and the volatility transmission network (Fig. 5b) reveals similar results.

\subsection{Rolling Window Spillover Analysis}

\subsubsection{Total Dynamic Spillovers in Oil Markets}

To include patterns of connectedness after periods of economic turmoil, especially the influence of the COVID-19 pandemic, the dynamic analysis was conducted. Figure 6 plots the time-varying total return and volatility connectedness of crude oil markets using the rolling-window regression. The total return connectedness was overall stable, range between almost $80 \%$ and $90 \%$ over time. Despite the slight spike occurs during the current COVID-19 pandemic. The total volatility spillover, denoted by the dashed line, was found to be more volatile, ranging from $55 \%$ to nearly $75 \%$. Notably, volatility spillover reached levels of approximately $75 \%$ on April, 2020. Such unprecedented high level of volatility connectedness gradually faded after June 2020, but still above the original magnitude. Given the fluctuations of the connectedness during the crisis, our results seem to confirm that the unforeseen shock has strengthened the links between crude oil markets.

\subsubsection{Net Directional Spillover of Individual Markets}

Observing the substantial changes of total spillover index during crisis, it is natural to ask whether the connectedness for individual markets has experienced a structural change during the analyzed sample period. Figures 7 and 8 collects the dynamic net return and volatility connectedness indexes as the difference between connectedness to and from.

\subsection{Return Spillover}

By observing Fig. 7, we can confirm that COVID-19 crisis seems to only exert temporary and small changes on the roles of the ten oil markets. Consistent with the 


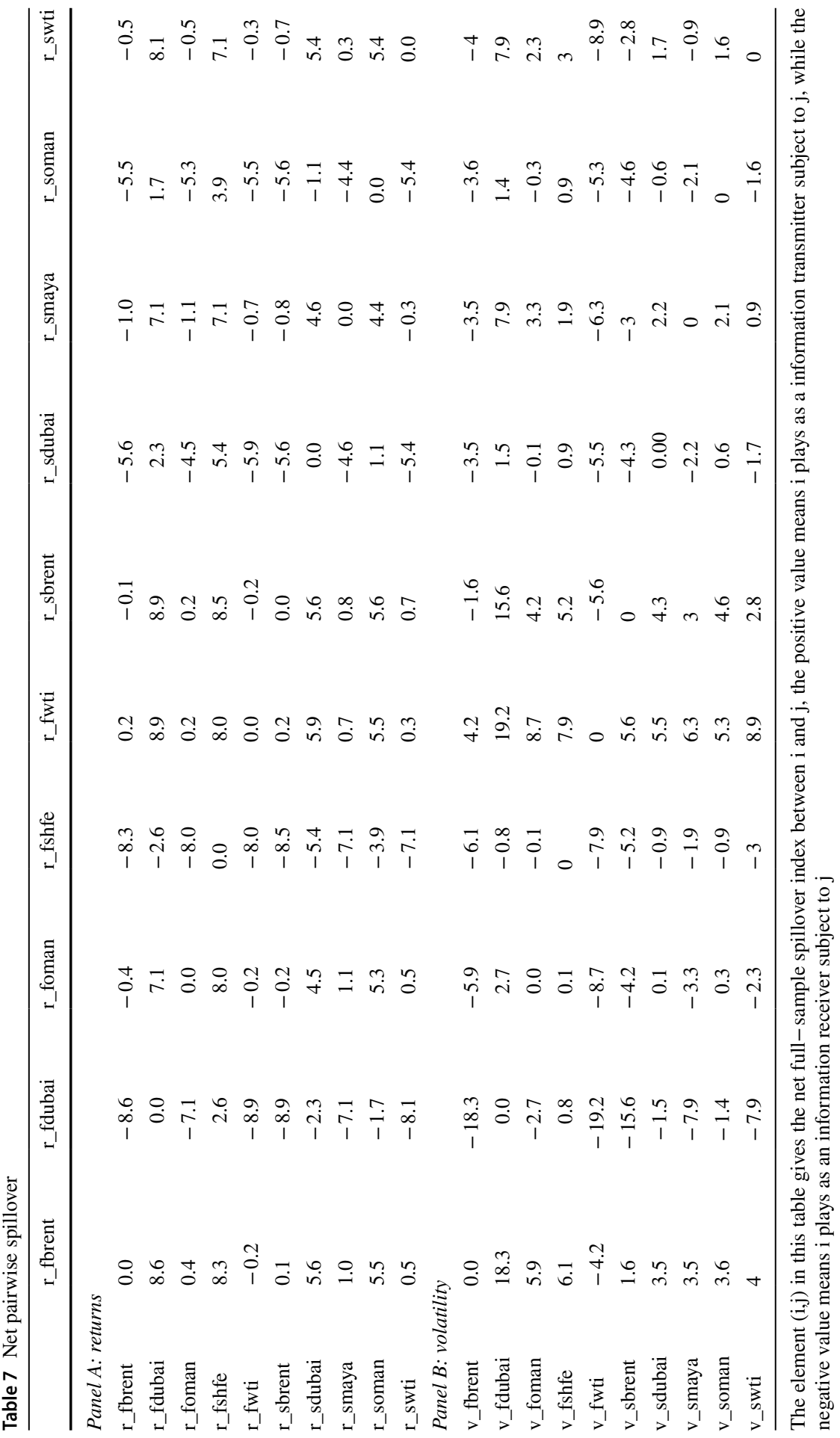




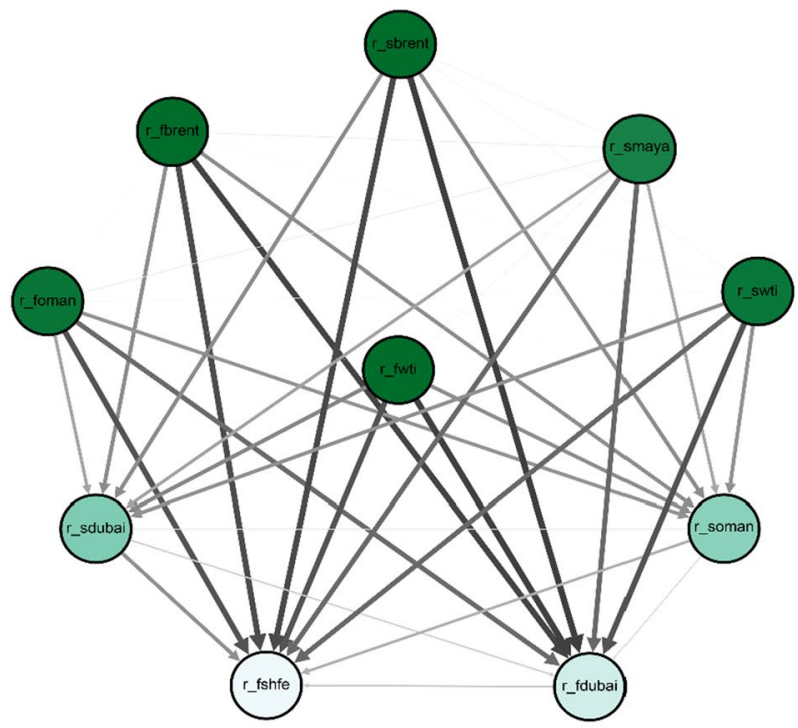

a return spillover

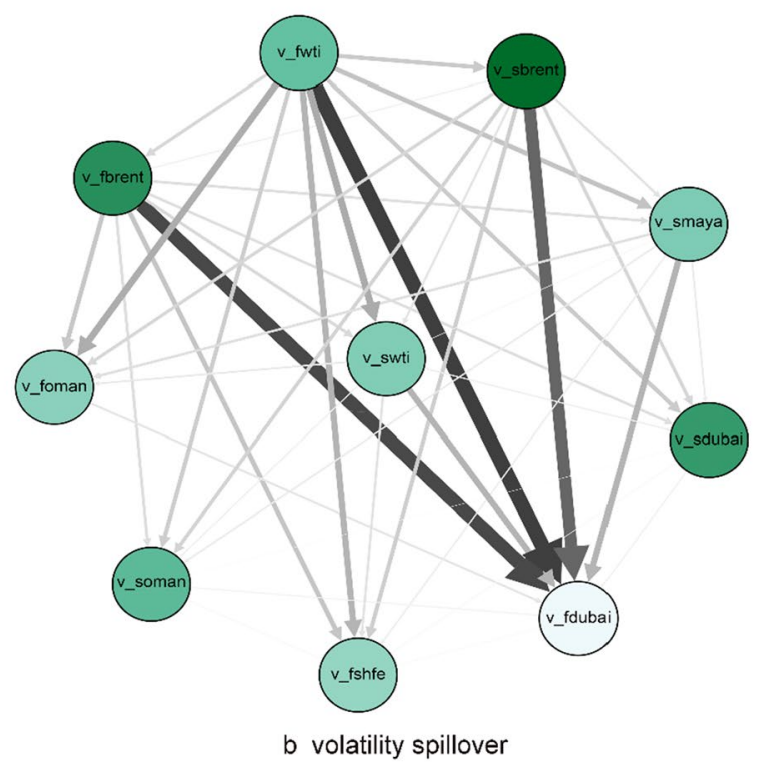

Fig. 5 Full sample net connectedness network, Notes The dark (or light) of the node's color indicates that it is a net transmitter (or receiver). The darker the color, the higher value of the net return and volatility spillover. The thickness of the edge indicates the magnitude of the pairwise return (or volatility) spillover between two nodes, the larger the magnitude of the spillover, the thicker the arrow. The arrow always points from a transmitter to a receiver 


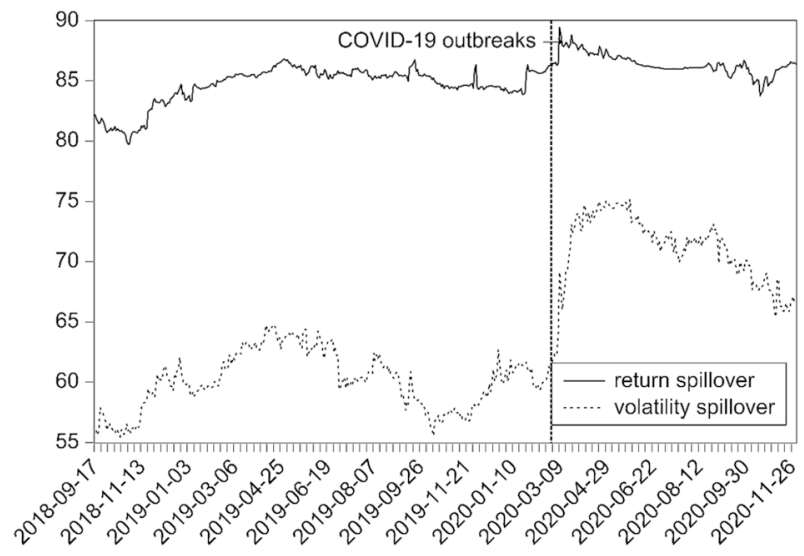

Fig. 6 Total return (solid line) and volatilities (dot line) spillover, ten oil markets, Note The dot line represents the day when the COVID-19 crisis outbreaks worldwide

preliminary results in full-sample analysis, Brent and WTI futures and spots are still the most influential oil commodity markets most of time. They were found to dominate with positive net connectedness, respectively transmitting $30 \%$ to $40 \%$ of the spillover to the system. They even continue to show the highest levels of return connectedness during the recent crisis caused by COVID-19. Other crude oil markets, such as Oman futures and Maya spot also exerted significant influences on the system. In contrast, Dubai spot and futures, Shanghai futures, and Oman spot markets shows a clear negative profile most of the time, indicating that those four markets served as net return receivers in the system.

However, focusing on the periods shortly after the COVID-19 crisis, we can observe that the return connectedness for different markets do not change in the same direction. The four net receivers in the system, namely, Dubai spot and futures, Oman spot, and Shanghai futures show an increase in the level of connectedness since March 2020 (as indicated by the right-hand side of the dotted line in Fig. 7), which contributed to the surge of the total return spillover for the whole system. It's interesting to note that Oman and Dubai crude oil spots even briefly shifted from receivers to transmitter from March to October 2020. Comparably, the COVID-19 pandemic was found to have minimal impact on net connectedness of Dubai futures and Shanghai futures, they were still the most relevant net receivers of return connectedness. Conversely, the level of net return connectedness decreases for WTI spot, Brent spot and Oman futures. Since March 2020, the return shocks from these three markets have declining influence on the system. Therefore, the difference between the net return connectedness measure after COVID-19 was narrowed.

\subsection{Volatility Spillover}

We then focus on the dynamic volatility connectedness of oil shocks from regional oil markets. Firstly, WTI and Brent futures are regarded as being the dominant net transmitters over the sample period. They respectively contributed approximately 

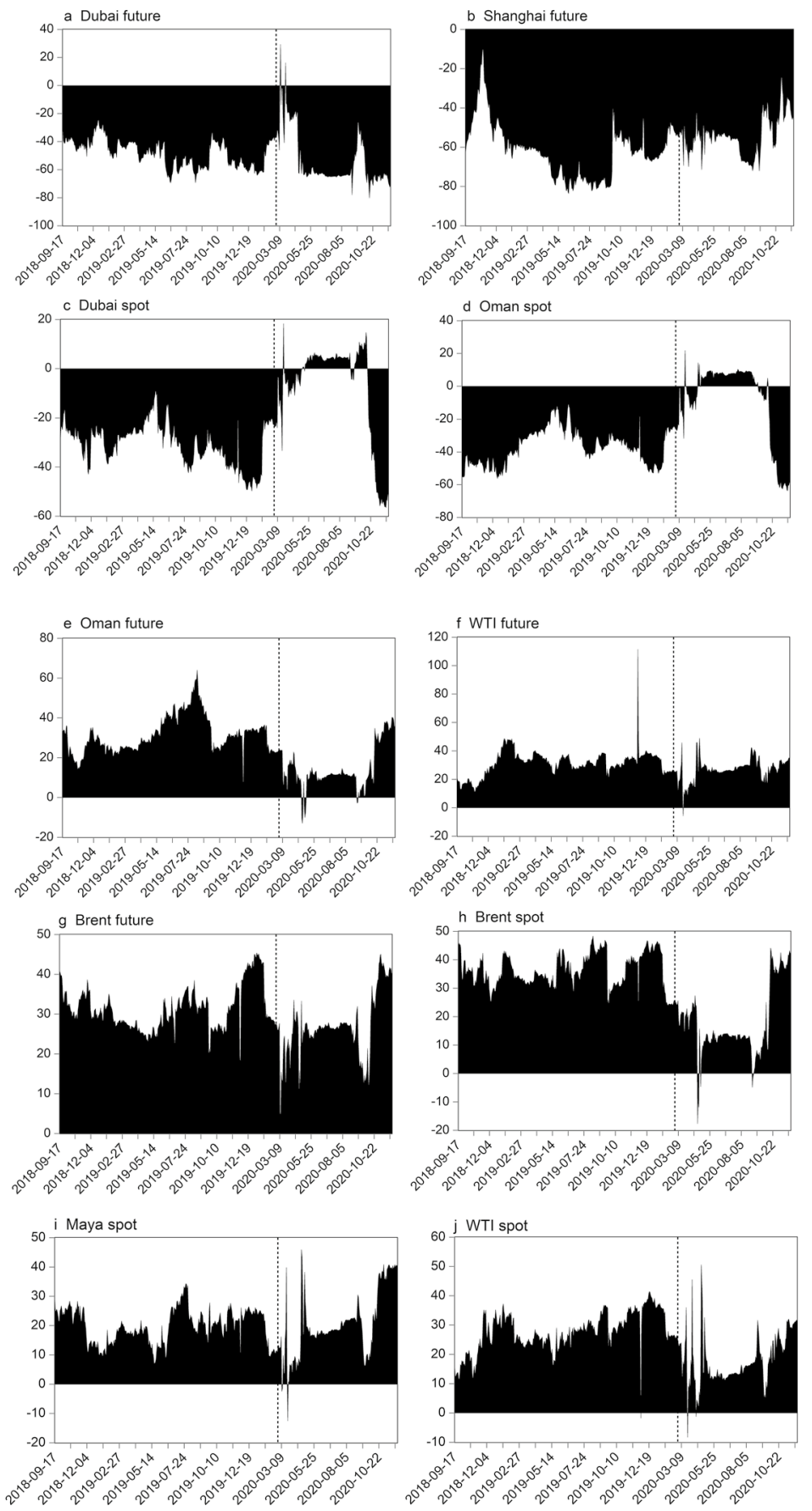

Fig. 7 Market net and aggregate return spillover, Note The dot line represents the day when the COVID19 crisis outbreaks worldwide 

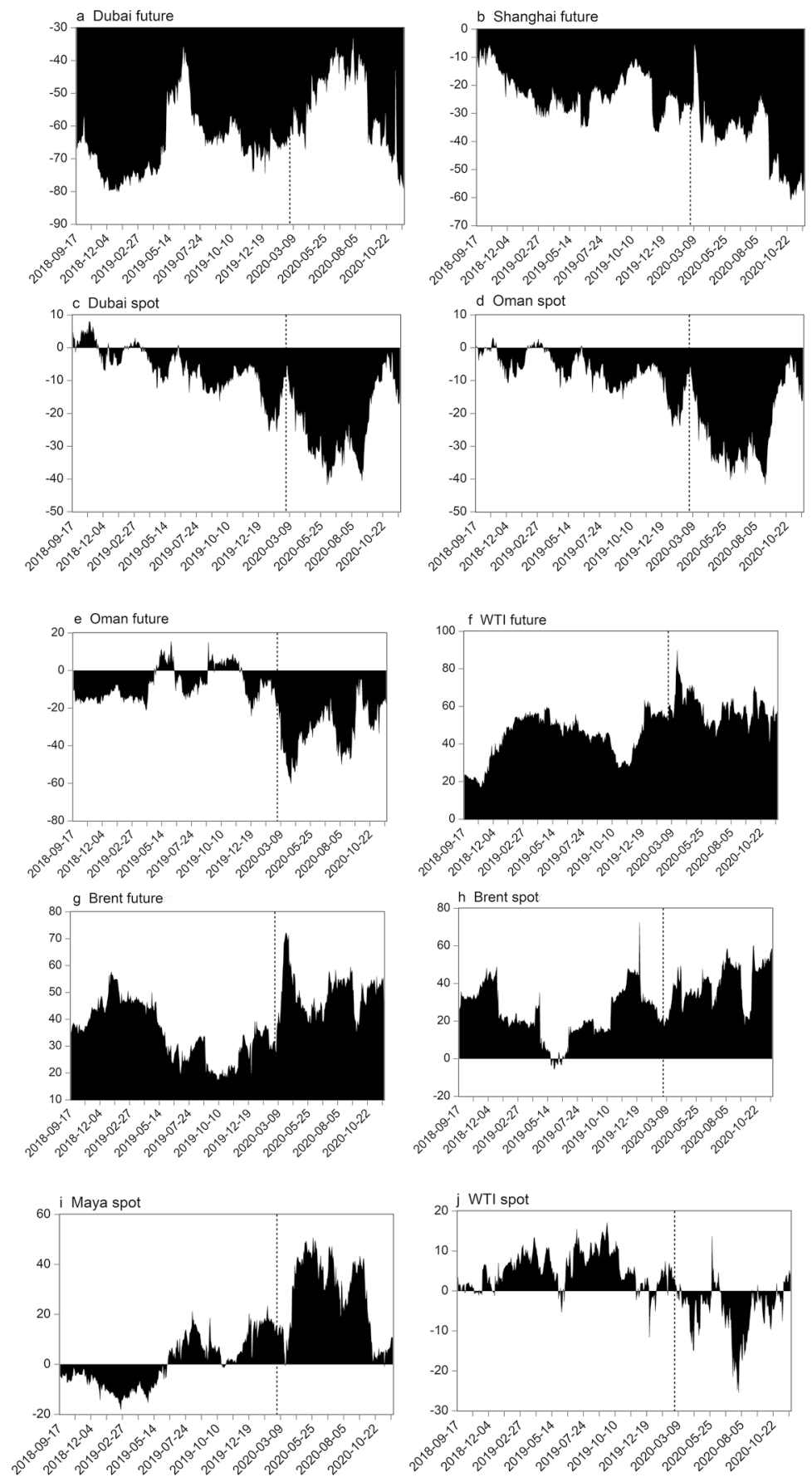

Fig. 8 Market net and aggregate volatility spillover, Note The dot line represents the day when the COVID-19 crisis outbreaks worldwide 
half of the net volatility connectedness to the whole system. The Brent spot also stands out as positive net transmitter, although it shows negative net volatility connectedness during June 2019. As net receivers, Dubai and Shanghai future appear as the dominant net receivers of volatility spillover before and after the COVID-19 crisis.

Compared with the net returns, the net volatility directional spillovers (Fig. 8) are not particularly high during periods of crisis, although we observe the difference between the volatility connectedness for oil markets has accentuated.

The shocks to the WTI futures, Brent futures, and Brent spot markets were found to exert slightly stronger impacts on the system after the worldwide outbreak of COIVD-19 (the right-hand side of the vertical dotted line).

WTI spot, Maya spot and Oman future, without very exact patterns of being net transmitter and receivers at the beginning of the rolling samples, switches between net receivers and net transmitter during the COVID-19 crisis from March to August, 2020, WTI and Oman future show very negative values as net receivers, and the latter even temporarily appears as the dominant net transmitter in the system. For the Maya spot, it switched from a net receiver into a net transmitter of volatility shocks, and its volatility connectedness has gradually increased to the peak of approximately $40 \%$.

As net receivers of volatility connectedness, we observe the increase in the level of volatility connectedness, from -70 to $-40 \%$ for Dubai futures. The remaining three net volatility spillover receivers, namely, Shanghai futures, Dubai and Oman spots were found to have picked up more information from other markets. The magnitude of volatility connectedness almost double as compared with their respective average spillover for the entire sample (26.7\% for Shanghai oil futures, $21.1 \%$ for Oman futures, $15.8 \%$ for Oman spot, $14.4 \%$ for Dubai spot).

The dynamic analysis reveals that the markets responded heterogeneously to the event. Although the patterns are less clear on the volatility connectedness, we can observe the COVID-19 crisis actually has strong impact on the net connectedness of oil markets.

\subsection{Robustness Check}

\subsubsection{Sub-Sample Analysis}

In this section, the static spillover analysis was conducted for three sub-samples, with one including one third of the total 649 trading days. The return and volatility connectedness tables for each sub-sample are presented in Tables 8 and 9, respectively.

COVID-19 crisis only drives up the total return connectedness index temporarily while exert larger impacts on volatility spillover. The total return connectedness was stable throughout the three sub-periods, with respective values of $81.2 \%, 83.2 \%$, and $82.6 \%$. In terms of the volatility, it increased from 56.1 and $58.0 \%$ in the first two subsamples to $69.5 \%$ in the last subsample. 


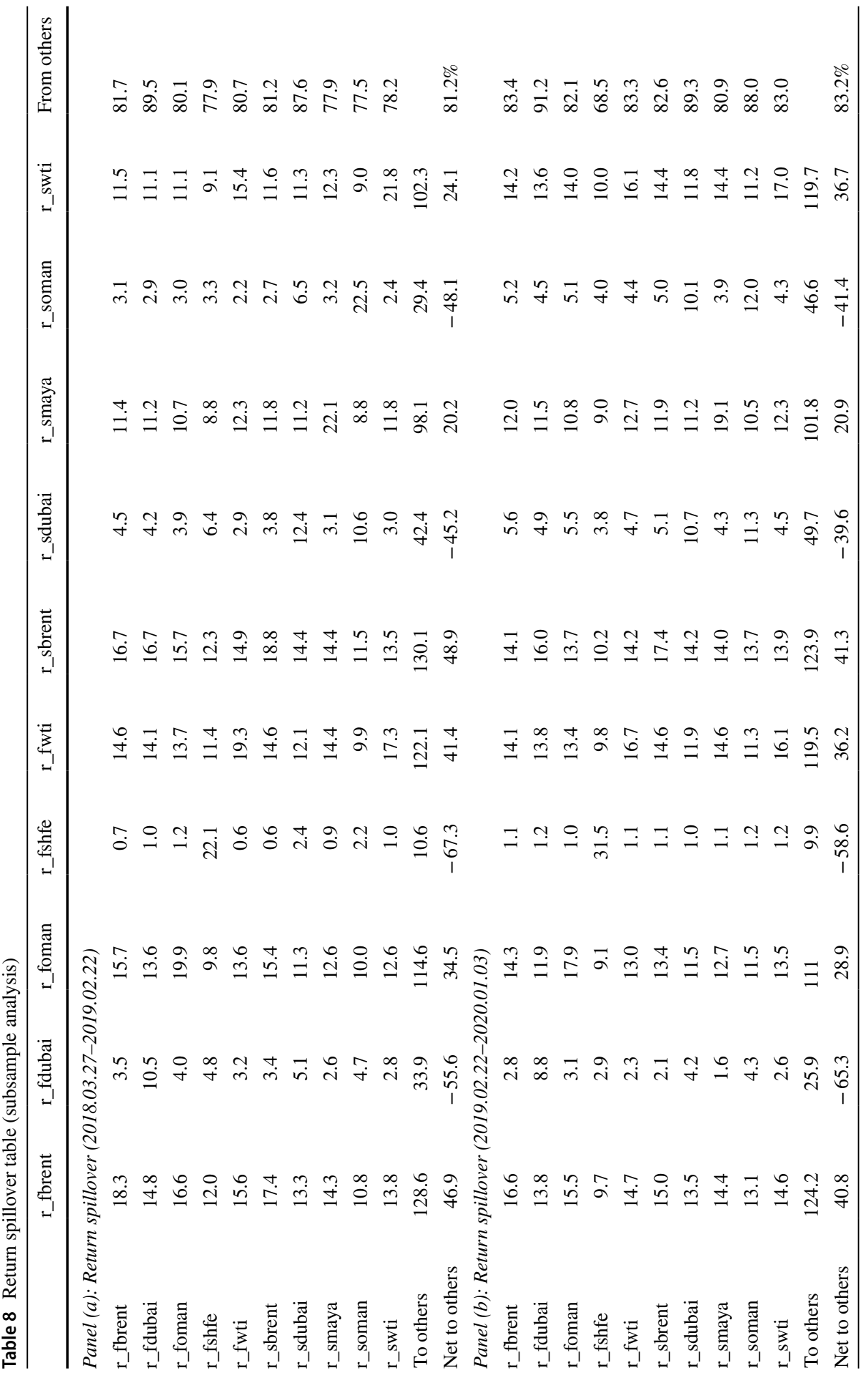




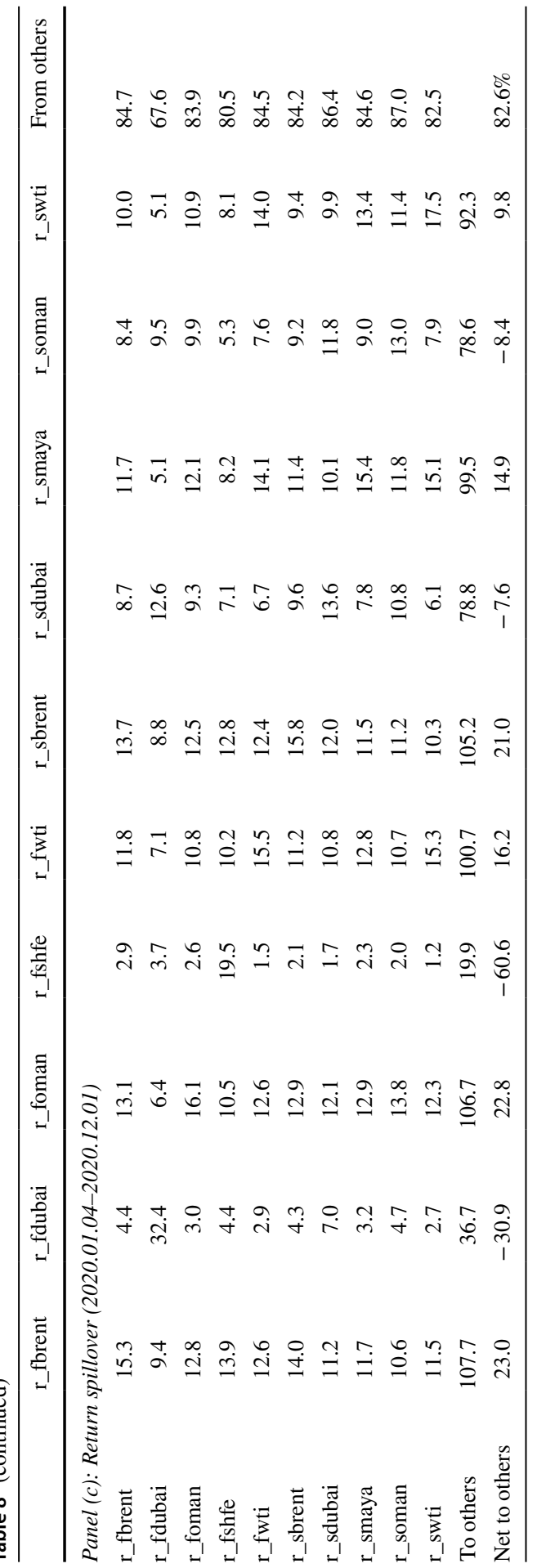




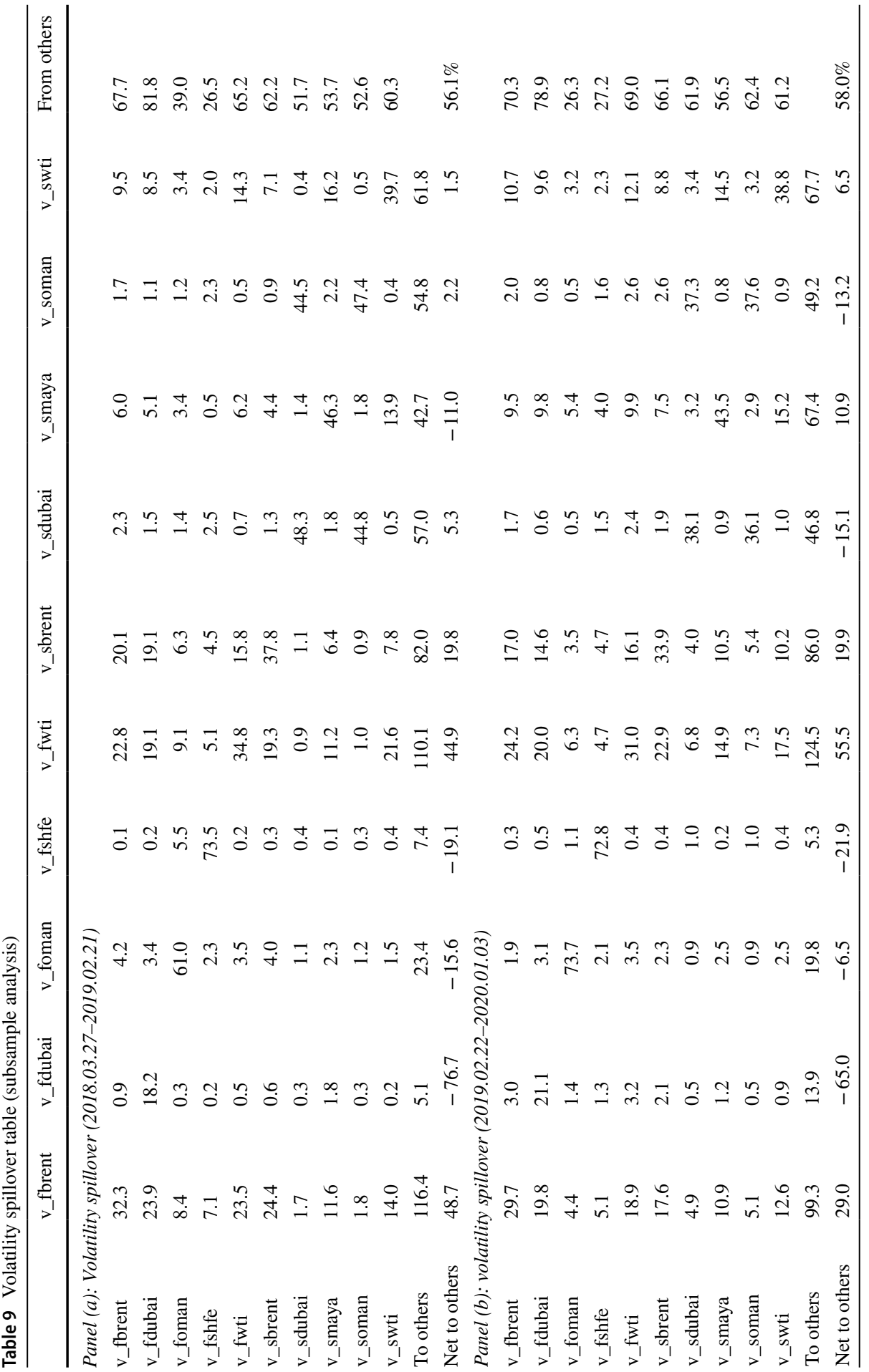




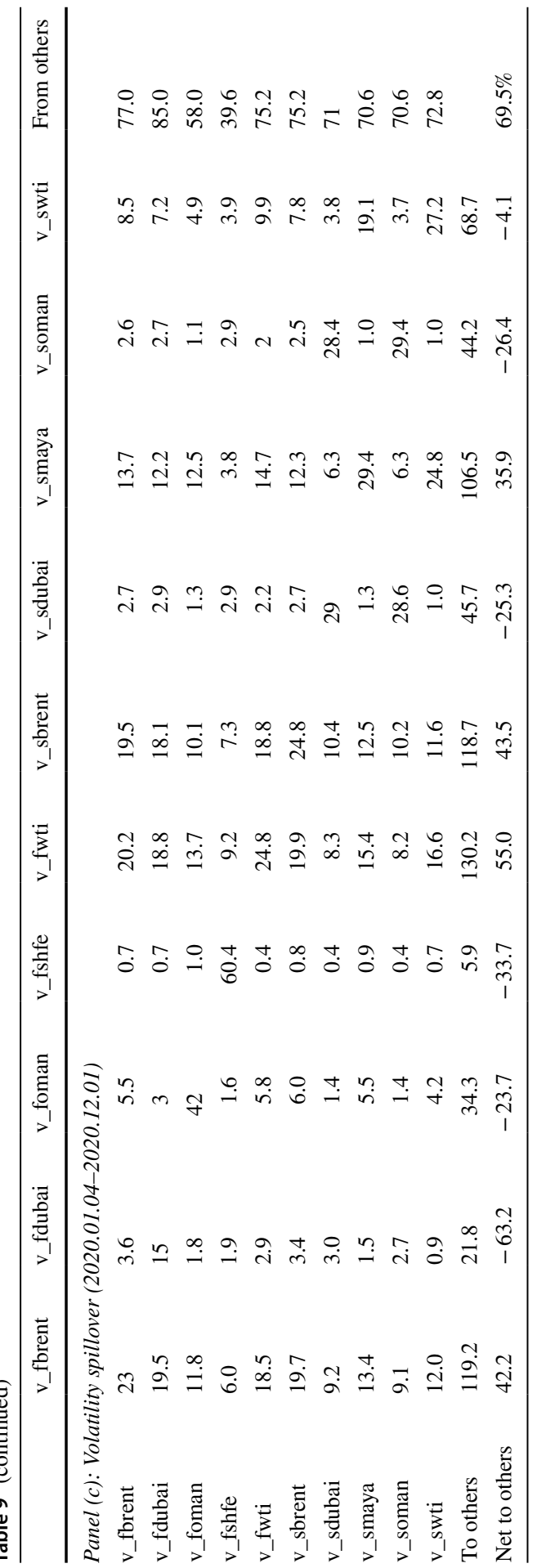


For individual markets, Brent futures, WTI futures, Brent spot are most dominant transmitter of return and volatility connectedness, and Dubai and Shanghai futures show net receivers profile in the oil markets for the three sub-samples.

For the return connectedness table in Table 8, we confirm that the difference of the net return connectedness narrowed during the period of COVID-19 crisis. It shows decreases in the level of net connectedness for three dominant net transmitters, while the net return connectedness has seen increased for net receivers, including Dubai future, Shanghai future, Dubai spot, and Oman spot.

The net volatility connectedness for each markets appeared quite varying patterns during the crisis. In terms of the net receivers, the empirical results in Table 9 support that, for Shanghai and Oman futures, and Oman and Dubai spots, the decrease in the net volatility spillover was found to result from the increase in the connectedness to the system, indicating that these four markets became more integrated into the global oil system during the crisis. Interestingly, as the most significant net receiver, the Dubai futures market was found to receive more than half of the net change in daily volatility from others, and its degree of integration with the system appeared to be lower after 2020. For net spillover transmitters, namely the Brent futures, WTI futures, and Brent spot markets. They still transmitted the most returns and volatility changes to the system in the net terms, and continue their leading roles. Besides, Oman futures, Maya and WTI spots switched between a net receiver to a net transmitter after the crisis.

In summary, the separate assessments of the return and volatility spillover effects for different sub-periods of the crude oil market confirm the findings of the empirical study presented in Sect. 5.3.

\subsubsection{TVP-VAR Connectedness Measures}

With the concerns of the arbitrary setting of the rolling-window size and the loss of the observations in limited time-series dataset, we assess the robustness of our dynamic connectedness results by comparing with time-varying parameter vector autoregression (TVP-VAR) model specifications proposed by the Antonakakis and Gabauer (2017). This TVP-VAR measure allows the variance to vary via a Kalman Filter estimation with forgetting factors. The generalized impulse response function (GIRF) and GFEVD are implemented to obtain the dynamic connectedness index.

Figure S1 plots the dynamic return and volatility connectedness index under the TVP-VAR methodology. Since the TVP-VAR without loss of observations, a longer period is included in the sample. Overall, we observe the dynamic total connectedness indices generated by the two methods show limited difference after the first rolling-window. The total connectedness index varied from 78 to $87 \%$ for return, and 53 to $73 \%$ for volatility. More importantly, we observe the significantly higher values of return and volatility connectedness after the crisis caused by the COVID-19.

Finally, we examine the robustness of our results for individual elements. Overall, we find that the dominant receivers and transmitter of return and volatility shocks are quite robust under the TVP-VAR specifications. Besides, the dynamic patterns of the connectedness, including the general behaviors, as well as the response to the COVID-19 shocks, are consistent with what we summarized in previous sections. 
More detailed results of dynamic return and volatility connectedness for individual market are provided in supplementary figures from Figs. S2 and S3.

\section{Conclusion and Discussion}

Using a recently widely used measurement of network connectedness proposed by Diebold and Yilmaz $(2009,2012,2014)$, this study provided a detailed examination of the return and volatility spillover effects for 10 global crude oil spot and futures contracts after the listing of Shanghai crude oil futures in the Shanghai INE. The results of this study provide some important insights into the understanding of how information was transmitted across the markets after the introduction of Shanghai oil futures. The empirical study was based on the rolling-window VAR regression using the daily price and intra-day volatility data from March 26th, 2018 to December 1st, 2020. In particular, the time-varying direction and magnitude of the spillover effects between different markets were evaluated, as were the impacts of a market event (the COVID-19 crisis) on these effects. The main findings of this paper can be summarized as follows.

First, the world's major crude oil spots and futures are quite closely interlinked with each other. For the entire sample, the aggregate return and volatility spillover indexes were found to be $85.2 \%$ and $64.3 \%$, respectively, which means that $85.2 \%$ $(64.3 \%)$ of the return (volatility) forecast error variances were due to the spillover effect among different markets. Moreover, the total connectedness across the 10 oil markets was found to intensify during the COVID-19 pandemic.

Second, in terms of the direction and magnitude of spillover, the results confirm the roles of the markets in the system; the WTI futures, Brent spot, and Brent futures markets were found to be the three leading contracts in the sample period, reflecting higher degrees of connectedness and stronger net spillover effects for other markets in the system. Dubai and Shanghai oil futures, as well as Dubai and Oman spots, are considered as major net information receivers. Among them, the Dubai oil futures market was found to be more central to the system than several other crude oil futures, receiving spillovers from several other markets and transmitting them to the entire oil market system. This is demonstrated by the fact that it was found to receive the most return and volatility spillover from other markets, and is therefore the more integrated into the system. In contrast, the degree of integration of Shanghai futures with the overall system requires further improvement.

Third, rolling-window regression was conducted to analyze the dynamics of spillovers across markets. It was found that each market changed very differently over the sample period in terms of both the direction and magnitude of the response to the shock. In the analysis, for the three contracts that produce the most return and volatility spillovers, the WTI futures and Brent spot markets were found to undergo a small decrease in spillover to this system during 2020, but still maintain their leading roles in the system. For Shanghai oil futures and Dubai and Oman spots, the decrease in net volatility spillover during the COVID-19 pandemic crisis was found to result from their higher integration into the global oil system, as they receive more return and volatility spillovers from 
others. However, Dubai futures experienced a significant drop in the spillover it received from other markets in 2020. Furthermore, interesting switching between being a receiver and transmitter was found for the Maya and WTI spot markets during COVID-19 crisis.

The Diebold and Yilmaz dynamic spillover index provides an opportunity to examine the contagion across regional crude oil markets during a crisis. The empirical results revealed that the DY index increased significantly during the COVID-19 pandemic period, especially for the intra-day volatility. Although the mechanism of market contagion was not explored more deeply in this paper, two explanations for the increase in contagion during the COVID-19 pandemic can be provided according to existing theory. First, in terms of macroeconomic fundamentals, the outbreak of the COVID-19 crisis led to a rise in macroeconomic uncertainty. The implemented blockade strategies, as well as plant shutdowns, resulted in a general decline in the global demand for crude oil for both transport and production. Moreover, crude oil markets exhibit a high degree of co-movement with other financial markets (Wen et al. 2012; Wei et al. 2019), Thus, in the face of a crisis, investors will rebalance their portfolios. As a financial product, crude oil is also subject to volatility from other financial markets, which weakens the effectiveness of portfolio diversification and increases the systematic risk (Fang and Egan 2018). In terms of investor behavior, the price of crude oil is no longer determined solely by its supply and demand, but has also shown to be financialized (Zhang and Broadstock 2018). The COVID-19 crisis led to volatility in oil prices, which subsequently created negative market expectations. These expectations propagated through the market, thereby causing the gradual convergence of market behavior among participants and significantly increasing the correlations between crude oil markets in different regions (Apergis et al. 2016; Ding et al. 2017). Diversified information channels, as well as online media, will allow information to be transmitted more rapidly and widely. A large number of investors will thereby reshape their expectations of the market, and will react quickly and dramatically. It can be expected that future financial markets will be more contagious than ever before.

As a result, commodities, which are characterized by high risk during a crisis, may no longer be the best choice for portfolio diversification. Investors will therefore need to pay close attention to the contagion effect across markets.

Supplementary Information The online version contains supplementary material available at https://doi. org/10.1007/s12076-021-00288-z.

Acknowledgements Jiasha Fu thanks the support by the China Social Science Fund (20\&ZD110). Anyremaining errors are the joint responsibility of the authors.

Authors' Contribution JF: conceptualization, writing- original draft preparation, writing-review and editing. HQ: software, data curation, formal analysis, writing-review and editing.

\section{Declarations}

Conflict of interest The authors declare that they have no known competing financial interests or personal relationships that could have appeared to influence the work reported in this paper. 


\section{References}

Adelman, M.A.: International oil agreements. Energy J (1984). https://doi.org/10.5547/ISSN0 195-6574-EJ-Vol5-No3

Andersen, T.G., Bollerslev, T., Diebold, F.X., Labys, P.: Modeling and forecasting realized volatility. Econometrica 71(2), 579-625 (2003). https://doi.org/10.1111/1468-0262.00418

Antonakakis, N., Gabauer, D. Refined measures of dynamic connectedness based on TVP-VAR. MPRA Paper No. 78282 (2017)

Apergis, N., Lau, M.C.K., Yarovaya, L.: Media sentiment and CDS spread spillovers: evidence from the GIIPS countries. Int. Rev. Financ. Anal. 47, 50-59 (2016). https://doi.org/10.1016/j.irfa.2016.06. 010

Baruník, J., Křehlík, T.: Measuring the frequency dynamics of financial connectedness and systemic risk. J. Financ. Economet. 16(2), 271-296 (2018). https://doi.org/10.1093/jjfinec/nby001

Baruník, J., Kočenda, E., Vácha, L.: Asymmetric connectedness on the US stock market: bad and good volatility spillovers. J. Financ. Mark. 27, 55-78 (2016). https://doi.org/10.1016/j.finmar.2015.09.003

Bouri, E., Cepni, O., Gabauer, D., Gupta, R.: Return connectedness across asset classes around the COVID-19 outbreak. Int. Rev. Financ. Anal. 73, 101646 (2021). https://doi.org/10.1016/j.irfa.2020. 101646

BP Statistical Review of World Energy (2019). https://www.bp.com/zh_cn/china/reports-and-publicatio ns/_bp_2019-_.html

Broadstock, D.C., Li, R., Wang, L.: Integration reforms in the European natural gas market: a rollingwindow spillover analysis. Energy Econ. 92, 104939 (2020). https://doi.org/10.1016/j.eneco.2020. 104939

Cai, Y., Chou, R.Y., Li, D.: Explaining international stock correlations with CPI fluctuations and market volatility. J. Bank. Finance 33(11), 2026-2035 (2009). https://doi.org/10.1016/j.jbankfin.2009.05. 013

Chang, C.L., McAleer, M., Tansuchat, R.: Analyzing and forecasting volatility spillovers, asymmetries and hedging in major oil markets. Energy Econ. 32(6), 1445-1455 (2010). https://doi.org/10.1016/j. eneco.2010.04.014

Chang, C.L., McAleer, M., Tansuchat, R.: Crude oil hedging strategies using dynamic multivariate GARCH. Energy Econ. 33(5), 912-923 (2011). https://doi.org/10.1016/j.eneco.2011.01.009

Dai, Y.H., Xie, W.J., Jiang, Z.Q., Jiang, G.J., Zhou, W.X.: Correlation structure and principal components in the global crude oil market. Emp. Econ. 51(4), 1501-1519 (2016). https://doi.org/10.1007/ s00181-015-1057-1

Diebold, F.X., Yilmaz, K.: Measuring financial asset return and volatility spillovers, with application to global equity markets. Econ. J. 119(534), 158-171 (2009)

Diebold, F.X., Yilmaz, K.: Better to give than to receive: predictive directional measurement of volatility spillovers. Int. J. Forecast. 28(1), 57-66 (2012). https://doi.org/10.1016/j.ijforecast.2011.02.006

Diebold, F.X., Yılmaz, K.: On the network topology of variance decompositions: measuring the connectedness of financial firms. J. Econom. 182(1), 119-134 (2014). https://doi.org/10.1016/j.jecon om.2014.04.012

Ding, Z., Liu, Z., Zhang, Y., Long, R.: The contagion effect of international crude oil price fluctuations on Chinese stock market investor sentiment. Appl. Energy 187, 27-36 (2017). https://doi.org/10. 1016/j.apenergy.2016.11.037

Eun, C.S., Shim, S.: International transmission of stock market movements. J. Financ. Quant. Anal. (1989). https://doi.org/10.2307/2330774

Fang, S., Egan, P.: Measuring contagion effects between crude oil and Chinese stock market sectors. Q. Rev. Econ. Finance 68, 31-38 (2018). https://doi.org/10.1016/j.qref.2017.11.010

Forbes, K.J., Rigobon, R.: No contagion, only interdependence: measuring stock market comovements. J. Financ. 57(5), 2223-2261 (2002). https://doi.org/10.1111/0022-1082.00494

Friendly, M.: Corrgrams: exploratory displays for correlation matrices. Am. Stat. 56(4), 316-324 (2002). https://doi.org/10.1198/000313002533

Gulen, S.G.: Regionalization in the world crude oil market: further evidence. Energy J. (1999). https:// doi.org/10.5547/ISSN0195-6574-EJ-Vol20-No1-7

Han, L., Kordzakhia, N., Trück, S.: Volatility spillovers in Australian electricity markets. Energy Econ. 90, 104782 (2020). https://doi.org/10.1016/j.eneco.2020.104782 
Ji, Q., Fan, Y.: Dynamic integration of world oil prices: a reinvestigation of globalisation vs. regionalisation. Appl. Energy 155, 171-180 (2015). https://doi.org/10.1016/j.apenergy.2015.05.117

Ji, Q., Zhang, D.: China's crude oil futures: introduction and some stylized facts. Financ. Res. Lett. 28, 376-380 (2019). https://doi.org/10.1016/j.frl.2018.06.005

Jia, X., An, H., Sun, X., Huang, X., Wang, L.: Evolution of world crude oil market integration and diversification: a wavelet-based complex network perspective. Appl. Energy 185, 1788-1798 (2017). https://doi.org/10.1016/j.apenergy.2015.11.007

Jin, X., Lin, S.X., Tamvakis, M.: Volatility transmission and volatility impulse response functions in crude oil markets. Energy Econ 34(6), 2125-2134 (2012). https://doi.org/10.1016/j.eneco.2012.03. 003

Kleit, A.N.: Are regional oil markets growing closer together? An arbitrage cost approach. Energy J. (2001). https://doi.org/10.5547/ISSN0195-6574-EJ-Vol22-No2-1

Koop, G., Pesaran, M.H., Potter, S.M.: Impulse response analysis in nonlinear multivariate models. J. Econom. 74(1), 119-147 (1996). https://doi.org/10.1016/0304-4076(95)01753-4

Korobilis, D., Yilmaz, K.: Measuring dynamic connectedness with large Bayesian VAR models (2018). https://doi.org/10.2139/ssrn.3099725

Kuck, K., Schweikert, K.: A Markov regime-switching model of crude oil market integration. J. Commod. Mark. 6, 16-31 (2017). https://doi.org/10.1016/j.jcomm.2017.03.001

Li, R., Leung, G.C.: The integration of China into the world crude oil market since 1998. Energy Policy 39(9), 5159-5166 (2011). https://doi.org/10.1016/j.enpol.2011.05.048

Lin, B., Su, T.: Does COVID-19 open a Pandora's box of changing the connectedness in energy commodities? Res. Int. Bus. Financ. 56, 101360 (2021). https://doi.org/10.1016/j.ribaf.2020.101360

Liu, T., Gong, X.: Analyzing time-varying volatility spillovers between the crude oil markets using a new method. Energy Econ. 87, 104711 (2020). https://doi.org/10.1016/j.eneco.2020.104711

Martens, M., Poon, S.H.: Returns synchronization and daily correlation dynamics between international stock markets. J. Bank. Finance 25(10), 1805-1827 (2001). https://doi.org/10.1016/S0378-4266(00) 00159-X

Milonas, N.T., Henker, T.: Price spread and convenience yield behaviour in the international oil market. Appl. Financ. Econ. 11(1), 23-36 (2001). https://doi.org/10.1080/09603100150210237

Pesaran, H.H., Shin, Y.: Generalized impulse response analysis in linear multivariate models. Econ. Lett. 58(1), 17-29 (1998). https://doi.org/10.1016/S0165-1765(97)00214-0

Scholes, M., Williams, J.: Estimating betas from nonsynchronous data. J. Financ. Econ. 5(3), 309-327 (1977). https://doi.org/10.1016/0304-405X(77)90041-1

Schotman, P.C., Zalewska, A.: Non-synchronous trading and testing for market integration in Central European emerging markets. J. Empir. Financ. 13(4-5), 462-494 (2006). https://doi.org/10.1016/j. jempfin.2006.04.002

Wei, Y., Qin, S., Li, X., Zhu, S., Wei, G.: Oil price fluctuation, stock market and macroeconomic fundamentals: evidence from China before and after the financial crisis. Financ. Res. Lett. 30, 23-29 (2019). https://doi.org/10.1016/j.frl.2019.03.028

Weiner, R.J.: Is the world oil market. Energy J. (1991). https://doi.org/10.5547/ISSN0 195-6574-EJ-Vol12-No3-7

Wen, X., Wei, Y., Huang, D.: Measuring contagion between energy market and stock market during financial crisis: a copula approach. Energy Econ. 34(5), 1435-1446 (2012). https://doi.org/10. 1016/j.eneco.2012.06.021

Reboredo, J.C.: How do crude oil prices co-move? A copula approach. Energy Econ. 33(5), 948-955 (2011). https://doi.org/10.1016/j.eneco.2011.04.006

Yang, J., Zhou, Y.: Return and volatility transmission between China's and international crude oil futures markets: a first look. J. Futur. Mark. 40(6), 860-884 (2020). https://doi.org/10.1002/fut.22103

Yang, K., Wei, Y., Li, S., Liu, L., Wang, L.: Global financial uncertainties and China's crude oil futures market: Evidence from interday and intraday price dynamics. Energy Econ. 96, 105149 (2021). https://doi.org/10.1016/j.eneco.2021.105149

Zhang, B., Wang, P.: Return and volatility spillovers between china and world oil markets. Econ. Model. 42, 413-420 (2014). https://doi.org/10.1016/j.econmod.2014.07.013

Zhang, D.: Oil shocks and stock markets revisited: Measuring connectedness from a global perspective. Energy Econ. 62, 323-333 (2017). https://doi.org/10.1016/j.eneco.2017.01.009

Zhang, D., Broadstock, D.C.: Global financial crisis and rising connectedness in the international commodity markets. Int. Rev. Financ. Anal. (2018). https://doi.org/10.1016/j.irfa.2018.08.003 
Zhang, D., Ji, Q., Kutan, A.M.: Dynamic transmission mechanisms in global crude oil prices: estimation and implications. Energy 175, 1181-1193 (2019). https://doi.org/10.1016/j.energy.2019.03.162

Zhou, X., Zhang, W., Zhang, J.: Volatility spillovers between the Chinese and world equity markets. Pac. Basin Financ. J. 20(2), 247-270 (2012). https://doi.org/10.1016/j.pacfin.2011.08.002

Publisher's Note Springer Nature remains neutral with regard to jurisdictional claims in published maps and institutional affiliations. 